\title{
Ice nucleation efficiency of natural dust samples in the immersion mode
}

\author{
Lukas Kaufmann $^{1}$, Claudia Marcolli ${ }^{1,2}$, Julian Hofer ${ }^{1,3}$, Valeria Pinti ${ }^{1}$, Christopher R. Hoyle ${ }^{4,5}$, and Thomas Peter ${ }^{1}$ \\ ${ }^{1}$ Institute for Atmospheric and Climate Science, ETH, Zurich, Switzerland \\ ${ }^{2}$ Marcolli Chemistry and Physics Consulting GmbH, Zurich, Switzerland \\ ${ }^{3}$ Leibniz Institute for Tropospheric Research (TROPOS), Leipzig, Germany \\ ${ }^{4}$ Laboratory of Atmospheric Chemistry, Paul Scherrer Institute, Villigen, Switzerland \\ ${ }^{5}$ WSL Institute for Snow and Avalanche Research SLF, Davos, Switzerland
}

Correspondence to: Claudia Marcolli (claudia.marcolli@env.ethz.ch)

Received: 18 April 2016 - Published in Atmos. Chem. Phys. Discuss.: 17 May 2016

Revised: 23 August 2016 - Accepted: 24 August 2016 - Published: 9 September 2016

\begin{abstract}
A total of 12 natural surface dust samples, which were surface-collected on four continents, most of them in dust source regions, were investigated with respect to their ice nucleation activity. Dust collection sites were distributed across Africa, South America, the Middle East, and Antarctica. Mineralogical composition has been determined by means of X-ray diffraction. All samples proved to be mixtures of minerals, with major contributions from quartz, calcite, clay minerals, K-feldspars, and ( $\mathrm{Na}, \mathrm{Ca}$ )-feldspars. Reference samples of these minerals were investigated with the same methods as the natural dust samples. Furthermore, Arizona test dust (ATD) was re-evaluated as a benchmark. Immersion freezing of emulsion and bulk samples was investigated by differential scanning calorimetry. For emulsion measurements, water droplets with a size distribution peaking at about $2 \mu \mathrm{m}$, containing different amounts of dust between 0.5 and $50 \mathrm{wt} \%$ were cooled until all droplets were frozen. These measurements characterize the average freezing behaviour of particles, as they are sensitive to the average active sites present in a dust sample. In addition, bulk measurements were conducted with one single $2 \mathrm{mg}$ droplet consisting of a $5 \mathrm{wt} \%$ aqueous suspension of the dusts/minerals. These measurements allow the investigation of the best icenucleating particles/sites available in a dust sample. All natural dusts, except for the Antarctica and ATD samples, froze in a remarkably narrow temperature range with the heterogeneously frozen fraction reaching $10 \%$ between 244 and $250 \mathrm{~K}, 25 \%$ between 242 and $246 \mathrm{~K}$, and $50 \%$ between 239 and $244 \mathrm{~K}$. Bulk freezing occurred between 255 and
\end{abstract}

$265 \mathrm{~K}$. In contrast to the natural dusts, the reference minerals revealed ice nucleation temperatures with 2-3 times larger scatter. Calcite, dolomite, dolostone, and muscovite can be considered ice nucleation inactive. For microcline samples, a $50 \%$ heterogeneously frozen fraction occurred above $245 \mathrm{~K}$ for all tested suspension concentrations, and a microcline mineral showed bulk freezing temperatures even above $270 \mathrm{~K}$. This makes microcline $\left(\mathrm{KAlSi}_{3} \mathrm{O}_{8}\right)$ an exceptionally good ice-nucleating mineral, superior to all other analysed K-feldspars, (Na, Ca)-feldspars, and the clay minerals. In summary, the mineralogical composition can explain the observed freezing behaviour of 5 of the investigated 12 natural dust samples, and partly for 6 samples, leaving the freezing efficiency of only 1 sample not easily explained in terms of its mineral reference components. While this suggests that mineralogical composition is a major determinant of ice-nucleating ability, in practice, most natural samples consist of a mixture of minerals, and this mixture seems to lead to remarkably similar ice nucleation abilities, regardless of their exact composition, so that global models, in a first approximation, may represent mineral dust as a single species with respect to ice nucleation activity. However, more sophisticated representations of ice nucleation by mineral dusts should rely on the mineralogical composition based on a source scheme of dust emissions. 


\section{Introduction}

Freezing of droplets consisting of liquid water or aqueous solutions and subsequent ice crystal growth affects microphysical and radiative properties of clouds and precipitation. Understanding and predicting the formation of ice in clouds is critical to quantifying the impact of aerosols on climate (DeMott et al., 2011). Ice crystals in the atmosphere may form by homogeneous ice nucleation of cloud droplets at temperatures $T<237 \mathrm{~K}$ or by heterogeneous ice nucleation under warmer conditions and possibly in the whole temperature range $T=237-273 \mathrm{~K}$. For heterogeneous nucleation, icenucleating particles (INPs), i.e. particles that initiate a phase transition in an environment supersaturated or supercooled with respect to ice, need to come in contact with (contact freezing), be immersed in (immersion freezing), and act as condensation nuclei for water droplets (condensation freezing), or present a surface for deposition of water vapour from the gas phase (deposition nucleation) (Pruppacher and Klett, 1997). Field measurements have shown that heterogeneous ice nucleation is indeed an important process in the atmosphere since ice formation in cumulus and stratiform clouds begins at temperatures much warmer than those associated with homogeneous ice nucleation in pure water (Korolev et al., 2003; Ansmann et al., 2009; Seifert al., 2010; Kanitz et al., 2011). Recently, Cziczo et al. (2013) suggested that heterogeneous ice nucleation might even have a dominating role in the formation of high, cold cirrus clouds.

INPs are generally rare and may represent less than 1 in $10^{6}$ of the aerosol particle population (DeMott et al., 2011). Various insoluble particles such as mineral dust, soot, metallic particles, volcanic ash, or primary biological particles have been suggested as INPs (Hoyle et al., 2011; Hoose and Möhler, 2012; Marcolli, 2014). The ability of mineral dusts to nucleate ice has been demonstrated in many laboratory experiments (Hoose and Möhler, 2012 and references therein; Marcolli, 2014 and references cited therein), and their impact on cloud properties has been shown in observational and modelling studies (Lohmann and Diehl, 2006; Hoose et al., 2010; Choi et al., 2010; Ansmann et al., 2008, 2009; Seifert et al., 2010). In mixed-phase clouds, mineral dust particles are usually the dominant INPs (Pratt et al., 2009; Kamphus et al., 2010) and were also found to be important for the heterogeneous freezing of cirrus clouds (DeMott et al., 2003; Twohy and Poellot, 2005; Cziczo et al., 2013).

The main sources of mineral dusts in the atmosphere are the arid regions in the world (Prospero et al., 2002; Ginoux et al., 2012). Model estimates indicate that global mineral dust emissions by wind-driven erosion range between 1000 and $3000 \mathrm{Tg} \mathrm{yr}^{-1}$ (Zender et al., 2004; Cakmur et al., 2006; Textor et al., 2007). The main source is the global dust belt, which stretches from the Sahara to the Taklimakan in China. Sources outside the global dust belt are deserts located in the USA and Mexico, Australia, Botswana and Namibia, Bolivia, and western Argentina (Sassen et al., 2003; En- gelstaedter et al., 2006; Formenti et al., 2011). From these source regions the dust may be transported in a wide altitude range over large distances (Wiacek and Peter, 2009; Wiacek et al., 2010; Engelstaedter et al., 2006; Li et al., 2008; Reid et al., 2003).

Immersion freezing is often considered the most important nucleation mode for mineral dusts (Hoose et al., 2010; Murray et al., 2012; Wiacek et al., 2010). The ability of mineral dusts to nucleate ice depends on their mineralogical composition (Murray et al., 2012; Atkinson et al., 2013), but may also be influenced by the presence of coatings or biological material (Möhler et al., 2008; Cziczo et al., 2009; Sullivan et al., 2010a; Conen et al., 2011; O'Sullivan et al., 2014; Tobo et al., 2014; Augustin-Bauditz et al., 2016). The surface structure and therefore the nucleation ability of mineral dust can change due to interaction with organic or inorganic substances. The effect of a coating depends on many different factors such as the mode of freezing, freezing temperature, and thickness and chemical composition of the coating $(\mathrm{Cz}-$ iczo et al., 2009; Chernoff and Bertram, 2010; Sullivan et al., 2010a, b; Tobo et al., 2012). Clay minerals and Arizona test dust (ATD) show a decrease of the ice nucleation ability due to coatings (Cziczo et al., 2009; Chernoff and Bertram, 2010; Sullivan et al., 2010a). Coatings that are acquired by dust particles during transport might be of minor importance for ice nucleation once a liquid cloud has formed and freezing occurs in immersion mode. In the absence of surface chemical reactions, the coating may dissolve in the cloud droplet so that the bare surface is exposed again and the ice-nucleating ability is restored (Sullivan et al., 2010b; Tobo et al., 2012; Kulkarni et al., 2014; Wex et al., 2014). Internal mixing of mineral dust particles with biological material is supposed to increase the ice nucleation ability of the dust and might occur during cotransport, during precipitation, or by lifting of soil particles (Baker et al., 2005; Pratt et al., 2009; Conen et al., 2011; Hallar et al., 2011; Creamean et al., 2013; O'Sullivan et al., 2014; Tobo et al., 2014; Augustin-Bauditz et al., 2016; Wang et al., 2016).

The most abundant components of mineral dusts are typically quartz, clay minerals, feldspars, and calcite (Murray et al., 2012; Boose et al., 2016). Clay minerals such as kaolinite, montmorillonite, or illite have usually been considered the main responsible components in mineral dusts for ice nucleation. Early studies indeed found kaolinite and montmorillonite among other minerals, as inclusions of atmospheric ice crystals (Kumai, 1961; Kumai and Francis, 1962). Many studies used therefore clay minerals as surrogates for mineral dusts (Hoose and Möhler, 2012; Welti et al., 2014; Wex et al., 2014; Wheeler et al., 2015; Augustin-Bauditz et al., 2014; Marcolli, 2014; Hiranuma et al., 2015; and citations therein). Recently, Atkinson et al. (2013) suggested that feldspar particles may account for a large proportion of INPs that contribute to freezing just below about $258 \mathrm{~K}$.

To investigate the role of mineral dust particles as INPs, and the dependence of ice nucleation activity on miner- 
alogical composition, natural dust samples from global dust source regions must be analysed. Dust collected directly from the air as well as dust collected from the ground in regions where dust events occur frequently should be compared with mineral reference samples in order to give new insights into the influence of mineral dusts on freezing in mixed-phase clouds. This study presents freezing results of natural dust samples collected from the ground at reported source regions of atmospheric mineral dust around the globe. To preserve the morphology, the only processing applied to the samples was sieving. We investigated whether the ice nucleation efficiency of the samples show significant differences between different source regions and whether the freezing behaviour can be related to the mineralogical composition. To this end, a set of reference minerals was subjected to freezing experiments using the same procedure as for the natural dust samples.

\section{Experimental setup}

For the immersion freezing measurements, we used a differential scanning calorimeter (DSC) Q10 from TA instruments. We performed both emulsion freezing and bulk freezing experiments: the former to characterize the average ice nucleation efficiency of dust particles; the latter to determine the temperature at which the best available ice-nucleating particles/sites in a dust sample are active.

For bulk freezing experiments the investigated dusts and minerals were mixed with water molecular biology reagent from Sigma-Aldrich, which proved to have lower average freezing temperatures of droplets compared with our Milli$\mathrm{Q}$ water. Of this suspension, a 1.8-2 mg droplet was placed in an aluminium pan, covered with mineral oil to avoid evaporation or condensation and finally hermetically sealed. The sample was subjected to repeated freezing cycles with $10 \mathrm{~K} \mathrm{~min}^{-1}$, which is a suitable cooling rate as the freezing temperature is given by a clear heat release onset due to the sudden freezing of the whole droplet. Bulk measurements were performed with a $5 \mathrm{wt} \%$ suspension. Blank bulk freezing experiments with the pure water showed freezing usually at approximately $250 \mathrm{~K}$. The highest freezing temperature of pure water was observed at $252.5 \mathrm{~K}$. Freezing at higher temperatures is therefore attributed to the presence of the dusts and minerals in the samples.

For emulsion freezing experiments, a quantity of sieved dust, or a powder of the mineral in the case of the reference samples, was mixed with water molecular biology reagent. Then, $20 \mathrm{vol} \%$ of this suspension plus $80 \mathrm{vol} \%$ of a mixture of $95 \mathrm{wt} \%$ mineral oil from Aldrich Chemical and $5 \mathrm{wt} \%$ lanolin from Fluka Chemical were emulsified with a rotor-stator homogenizer (Polytron PT 1300D with a PT-DA 1307/2EC dispersing aggregate) during $40 \mathrm{~s}$ at $7000 \mathrm{rpm}$. Next, $4-15 \mathrm{mg}$ of this emulsion was placed in an aluminium pan, hermetically sealed, and subjected to three freezing cycles following the method developed by Marcolli et al. (2007). The first and the third freezing cycles were executed at a cooling rate of $10 \mathrm{~K} \mathrm{~min}^{-1}$ to control the stability of the sample. The second freezing cycle was executed at a $1 \mathrm{~K} \mathrm{~min}^{-1}$ cooling rate and was used for evaluation. The evaluation was done using the implemented software (TA Universal Analysis) of the instrument. The heterogeneous freezing peak was analysed in terms of three characteristic temperatures that correspond to $10 \%\left(T_{\text {het }}, 10 \%\right), 25 \%$ $\left(T_{\text {het, } 25 \%}\right)$, and $50 \%\left(T_{\text {het, } 50 \%}\right)$ of heterogeneously frozen water volume. This value was obtained by integrating over the heat flow signal of the heterogeneous freezing peak and setting the total heterogeneous heat flow to $100 \%$. If the homogeneous and heterogeneous peaks overlapped, the heterogeneous peak was assumed to end where the heterogeneous peak shape was clearly influenced by the homogeneous peak (see Appendix A for further information). The integrals over the heterogeneous and homogeneous peaks are used to calculate the ratio between homogeneous and heterogeneous freezing. Emulsion measurements were performed with $0.5,1,2,5$, and $10 \mathrm{wt} \%$ mineral dust suspensions. For calcite, dolomite, dolostone, and ankerite it was hardly possible to evaluate the 10,25 , and $50 \%$ heterogeneously frozen water volume because of a very weak heterogeneous freezing signal. Due to this, these minerals were also measured with $50 \mathrm{wt} \%$ suspension concentration, and onset temperatures were evaluated. The evaluation method for onset temperatures is described in Zobrist et al. (2006). Very abrupt but small spikes are excluded from the evaluation, because they originate from single droplets in the tail of the size distribution, which are orders of magnitude larger in volume than the average droplets. For dust samples with many large particles (from micrometres upwards), spikes were more frequent. Comparison of the evaluated temperatures for different samples of the same dust with the same concentration usually showed standard deviations of $0.5 \mathrm{~K}$. Samples with weak heterogeneous signal or with spikes overlapping the smooth heterogeneous signal developed standard deviations up to $1 \mathrm{~K}$.

Pictures for the evaluation of the size distribution of emulsion droplets were taken with an optical microscope (Olympus BX-40). Ten different emulsions containing a total of 1700 droplets were analysed. The droplet diameter was evaluated with the free image processing and analysis program ImageTool (from the University of Texas Health Science Center at San Antonio), grouped into bins with a width of $0.5 \mu \mathrm{m}$ from 0 to $10 \mu \mathrm{m}$, and fitted with a lognormal number distribution

$N(d)=\frac{N_{0} e^{w^{2} / 2}}{\sqrt{2 \pi} w d} e^{-\frac{\ln ^{2}\left(d / d_{\mathrm{m}}\right)}{2 w^{2}}}$,

giving $d_{\mathrm{m}}=(2.41 \pm 0.04) \mu \mathrm{m}$ as the droplet mode diameter, and $w=0.507 \pm 0.014$ as the mode width, where $N_{0}$ is the total number of droplets. The volume distribution was fitted 


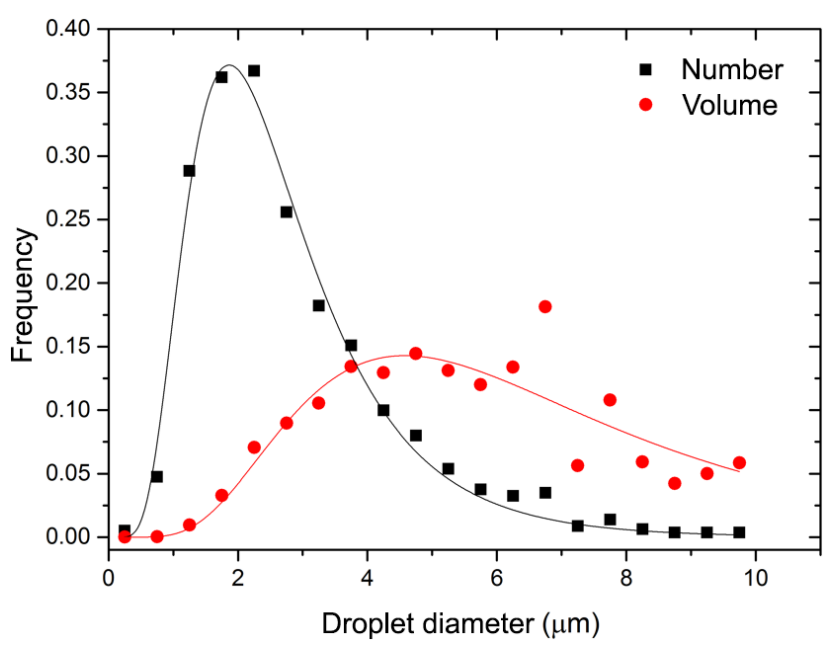

Figure 1. Normalized lognormal size distribution of emulsion droplets. Data points represent bin widths of $0.5 \mu \mathrm{m}$. The parameters for the lognormal number distribution are $d_{\mathrm{m}}=2.41 \pm 0.04 \mu \mathrm{m}$ and $w=0.507 \pm 0.014$, and for the volume distribution $d_{\mathrm{m}}=$ $6.1 \pm 0.4 \mu \mathrm{m}$ and $w=0.53 \pm 0.05$.

with the function

$V(d)=\frac{V_{0} e^{w^{2} / 2}}{\sqrt{2 \pi} w d} e^{-\frac{\ln ^{2}\left(d / d_{\mathrm{m}}\right)}{2 w^{2}}}$,

where $d_{\mathrm{m}}=(6.1 \pm 0.4) \mu \mathrm{m}, w=0.53 \pm 0.05$, and $V_{0}$ is the total volume of all droplets. The obtained number and volume distributions are shown in Fig. 1.

The natural dust samples were sieved with a $32 \mu \mathrm{m}$ sieve. Sieving was performed with the dry samples. No other pretreatment was applied, except for the Antarctica sample for which a milled sample was used in addition to the sieved sample.

Size distributions of the sieved natural dusts and the milled reference minerals were measured with a TSI 3080 scanning mobility particle sizer (SMPS) and with a TSI 3321 aerodynamic particle sizer (APS) and combined as described by Beddows et al. (2010). The bulk powders were aerosolized in a fluidized bed aerosol generator (TSI Model 3400A) to determine the size distributions with SMPS and APS. Similar to the size distributions of the emulsion droplets, also the dust number size distributions were fitted to a lognormal distribution. Results are given in Table 1. Reference minerals were provided by the Institute of Geochemistry and Petrology of ETH Zurich and milled with a tungsten carbide ball mill. No additional treatment was applied.

The mineralogical composition of the sieved natural dust samples and the milled reference samples was measured by $\mathrm{X}$-ray diffraction (XRD). A quantitative analysis was performed with the AutoQuan program which is a commercial product of GE inspection technologies and which makes a Rietveld refinement (Rietveld, 1967, 1969).

\section{Statistical evaluation of emulsion measurements}

Knowing the droplet size distribution of the emulsions and the size distribution of the dust particles, the theoretical value for the latent heat release for homogeneous and heterogeneous freezing can be estimated. This theoretical value can be directly compared with the measured latent heat release by the DSC.

To calculate the total number of mineral dust particles in an emulsion, the average volume of particles $\bar{V}_{\mathrm{p}}$ was calculated by

$\bar{V}_{\mathrm{p}}=\int_{0}^{\infty} N(r) \frac{4}{3} \pi r^{3} \mathrm{~d} r$,

where $N(r)$ is the normalized particle size distribution of the respective mineral/dust as a function of its radius $r$. With the mass of the dust, $m_{\text {dust }}$, and assuming a density of dust, $\rho_{\text {dust }}=2.6 \mathrm{~g} \mathrm{~cm}^{-3}$ (Möhler et al., 2006), the number of dust particles $n$ in an emulsion can be estimated to be

$n=\frac{m_{\text {dust sample }}}{\rho_{\text {dust }} \bar{V}_{\mathrm{p}}}$.

The probability $P_{j}$ for a particle to be in a droplet $j$ with a volume $V_{j}$ is $P_{j}=V_{j} / V_{\text {tot }}$, where $V_{\text {tot }}$ is the total volume of all droplets in the emulsion. Assuming $n$ particles in the emulsion, which are all distributed among the water droplets, the probability for no particle in a droplet $j$ with a volume $V_{j}$ is $\left(1-V_{j} / V_{\text {tot }}\right)^{n}$. The contribution of droplet $j$ to the total heterogeneous and homogeneous peak area $A_{\text {tot }}$ is proportional to $V_{j} / V_{\text {tot }}$. The percentage of homogeneous freezing, $p_{\text {hom }}$, can then be written as

$p_{\mathrm{hom}}=\sum_{j=1}^{k} \frac{V_{j}}{V_{\mathrm{tot}}} \cdot\left(1-\frac{V_{j}}{V_{\mathrm{tot}}}\right)^{n}$,

where $k$ is the number of droplets. The fraction of heterogeneously frozen volume $p_{\text {het }}$ is then

$p_{\text {het }}=1-p_{\text {hom }}$.

Like this, we are able to calculate the heterogeneously frozen water volume under the assumption that all mineral dust particles are able to induce heterogeneous freezing.

The fraction of heterogeneously frozen volume measured with the DSC ( $\left.p_{\text {het,lab }}\right)$ is calculated by dividing the latent heat release of the heterogeneous freezing signal by the latent heat release of the total freezing signal (homogeneous plus heterogeneous). The number of mineral dust particles, $n_{\text {lab }}$, necessary to explain the heterogeneously frozen volume fraction can be obtained by solving the equation

$p_{\text {het, lab }}=1-\sum_{j=1}^{k} \frac{V_{j}}{V_{\text {tot }}} \cdot\left(1-\frac{V_{j}}{V_{\text {tot }}}\right)^{n_{\text {lab }}}$ 
Table 1. Lognormal size distribution parameters $d_{\mathrm{m}}(\mathrm{nm})$ and $w$ for the analysed samples according to Eq. (1). Error ranges reflect fit uncertainties. For the Oman and Qatar samples not enough material was available to measure the size distribution.

\begin{tabular}{|c|c|c|c|}
\hline Category & Mineral/dust & $d_{\mathrm{m}}(\mathrm{nm})$ & $w$ \\
\hline \multirow[t]{3}{*}{ Antarctica and ATD } & Antarctica & $383 \pm 3$ & $0.542 \pm 0.005$ \\
\hline & Antarctica milled & $288 \pm 0.8$ & $0.443 \pm 0.002$ \\
\hline & ATD & 354 & 0.609 \\
\hline \multirow{8}{*}{$\begin{array}{l}\text { Natural dust } \\
\text { source regions }\end{array}$} & Bolivia & $216 \pm 1.9$ & $0.603 \pm 0.006$ \\
\hline & Etosha & $414 \pm 6$ & $0.797 \pm 0.008$ \\
\hline & Hoggar & $312 \pm 2$ & $0.609 \pm 0.004$ \\
\hline & Israel 1 & $401 \pm 2$ & $0.554 \pm 0.004$ \\
\hline & Israel 2 & $479 \pm 4$ & $0.545 \pm 0.005$ \\
\hline & Makgadikgadi A & $354 \pm 3$ & $0.632 \pm 0.004$ \\
\hline & Makgadikgadi B & $283 \pm 1.9$ & $0.694 \pm 0.004$ \\
\hline & Makgadikgadi C & $274 \pm 2$ & $0.678 \pm 0.005$ \\
\hline \multicolumn{4}{|l|}{ Reference minerals } \\
\hline \multirow[t]{6}{*}{ Naturally abundant } & Ankerite & $329 \pm 1.5$ & $0.592 \pm 0.003$ \\
\hline & Calcite & $283 \pm 3$ & $0.504 \pm 0.007$ \\
\hline & Dolomite & $304 \pm 2$ & $0.536 \pm 0.005$ \\
\hline & Dolostone & $380 \pm 1.7$ & $0.529 \pm 0.003$ \\
\hline & Muscovite & $335 \pm 6$ & $0.558 \pm 0.011$ \\
\hline & Quartz & $364.5 \pm 1.8$ & $0.528 \pm 0.003$ \\
\hline \multirow[t]{7}{*}{ K-feldspars } & Adularia 1 & $349 \pm 1.8$ & $0.528 \pm 0.004$ \\
\hline & Adularia 2 & $249 \pm 0.5$ & $0.544 \pm 0.002$ \\
\hline & Microcline Elba & $399 \pm 2$ & $0.530 \pm 0.003$ \\
\hline & Microcline Namibia & $412 \pm 3$ & $0.531 \pm 0.004$ \\
\hline & Orthoclase 1 & $417 \pm 3$ & $0.528 \pm 0.004$ \\
\hline & Orthoclase 2 & $262.8 \pm 0.9$ & $0.590 \pm 0.002$ \\
\hline & Sanidine & $372.5 \pm 1.5$ & $0.524 \pm 0.003$ \\
\hline \multirow[t]{4}{*}{ (Na, Ca)-feldspars } & Albite (pericline) & $439 \pm 3$ & $0.548 \pm 0.005$ \\
\hline & Anorthite & $336 \pm 3$ & $0.523 \pm 0.005$ \\
\hline & Labradorite & $467 \pm 4$ & $0.528 \pm 0.005$ \\
\hline & Plagioclase & $404 \pm 2$ & $0.499 \pm 0.004$ \\
\hline \multirow[t]{9}{*}{ Clay minerals } & Illite NX & $354 \pm 4$ & $0.625 \pm 0.008$ \\
\hline & Illite SE & $317 \pm 3$ & $0.576 \pm 0.006$ \\
\hline & KGa-1b & $302 \pm 4$ & $0.585 \pm 0.009$ \\
\hline & KGa-2 & $353 \pm 4$ & $0.562 \pm 0.007$ \\
\hline & $\mathrm{K}-\mathrm{SA}$ & $416 \pm 5$ & $0.609 \pm 0.007$ \\
\hline & M K-10 & $395 \pm 4$ & $0.584 \pm 0.007$ \\
\hline & M KSF & $453 \pm 12$ & $0.628 \pm 0.016$ \\
\hline & M STx-1b & $278 \pm 4$ & $0.655 \pm 0.010$ \\
\hline & M SWy-2 & $279 \pm 4$ & $0.647 \pm 0.008$ \\
\hline
\end{tabular}

for $n_{\text {lab }}$. The active fraction $f_{\text {act }}$ of dust or mineral particles, i.e. the fraction of particles that are active as INPs, can then be calculated by

$f_{\text {act }}=\frac{n_{\text {lab }}}{n}$.

Correspondingly, $1-f_{\text {act }}$ is the fraction of dust (or mineral) particles that remain inactive to the point that droplets freeze homogeneously. By calculating the heterogeneously frozen fraction $p_{\text {het,lab }}$ as a sum of droplet volume bins, it is taken into account that freezing of a larger droplet contributes more to the latent heat signal than freezing of a smaller droplet. The probability for a droplet to contain at least one particle depends on its volume. With increasing volume the probability increases that a droplet contains at least one particle. Therefore, the probability for a larger water droplet to freeze heterogeneously is higher than for a smaller water droplet. Hence, freezing of larger droplets dominates the heterogeneous freezing signal and freezing of smaller droplets the homogeneous freezing signal. For example, assuming the latent heat release of the heterogeneous freezing signals to be 


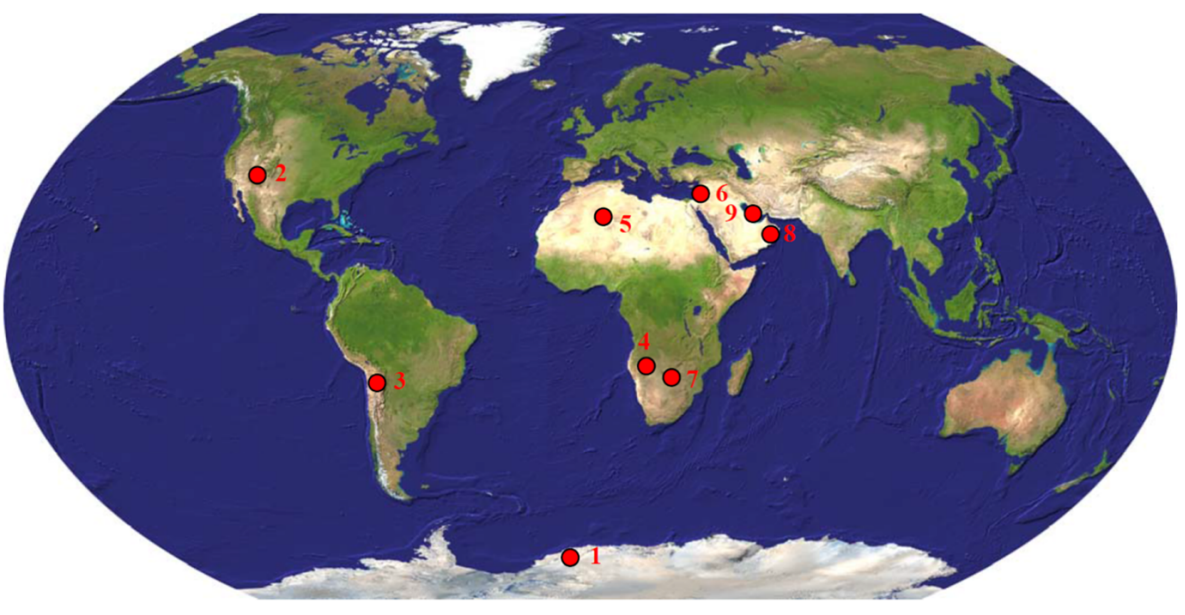

Figure 2. Collection locations of natural dust samples (in alphabetical order): (1) Antarctica, (2) Arizona, (3) Bolivia, (4) Etosha, (5) Hoggar, (6) Israel, (7) Makgadikgadi, (8) Oman, (9) Qatar.

the same as the latent heat release of the homogeneous freezing signal, the heterogeneous freezing signal represents the freezing of fewer larger droplets and the homogeneous freezing signal the freezing of a high number of smaller droplets.

\section{Minerals and dust samples}

\subsection{Dust samples}

Natural dust samples have been collected from Antarctica, Bolivia, Etosha (Namibia), Israel, Makgadikgadi (Botswana), Oman, and Qatar. For comparison, commercially available ATD was also investigated. The geographical locations of all eight sampling sites are shown in Fig. 2. The natural dusts are briefly characterized below.

1. The Antarctica sample was collected at $74^{\circ} 16.5^{\prime} \mathrm{S}$ and $9^{\circ} 37.3^{\prime} \mathrm{W}$ at an altitude of $1520 \mathrm{~m}$ above sea level. Antarctica is generally not considered as a source region for atmospheric dust, rather, dusts from dominant dust source regions in the Southern Hemisphere reach Antarctica (Revel-Rolland et al., 2006; Winckler et al., 2008; Li et al., 2008; Genthon, 1992). Nevertheless, the fine (sieved) fraction of the Antarctica sample is not transported dust but from local erosion, because it exhibited a very similar XRD pattern as larger grains or gravels from the same sample that are too large to be transported. To see the influence of milling, the fine fraction (particles $<32 \mu \mathrm{m}$ ) of the Antarctica sample was also milled.

2. Arizona test dust (ATD) is a commercial dust sample that has been used by many investigators as a proxy of natural atmospheric mineral dust (Murray et al., 2012). It is produced by grinding samples of sand from Ari- zona. It is described in detail by Möhler et al. (2006) and Knopf and Koop (2006).

3. The Bolivia sample was collected in the surroundings of the Laguna Verde in the southern part of Bolivia. The salt flats on the Altiplano including Laguna Verde are important dust sources in South America (Goudie and Wells, 1995; Washington et al., 2003).

4. The Etosha sample was collected in the Etosha pan in the northern region of Namibia. The pan was formed by a lake which dried out. Bryant et al. (2007), Prospero et al. (2002), and Washington et al. (2003) describe the Etosha pan as one of the principle dust sources in southern Africa. The Etosha sample was collected $18.86^{\circ} \mathrm{S}$ and $16.70^{\circ} \mathrm{E}$ at the eastern part of the pan.

5. Hoggar Mountain dust was collected from the Sahara region (Pinti et al., 2012). It is a mixture of minerals originating from a source region with high shares of clay minerals (Pinti et al., 2012). According to Laurent et al. (2010) the Hoggar Mountains are part of a region which has been identified as a major source for desert dust aerosols.

6. The Israel samples were collected close to Sde Boker in a dried out river bed. Poor vegetation is present in this region. The region itself is frequently exposed to desert dust due to its position at the northern end of the Negev desert, but is not itself believed to be a supra-regional atmospheric dust source (Prospero et al., 2002).

7. The Makgadikgadi samples were collected in the Makgadikgadi pans in the northeast of Botswana. In the past there were lakes which dried out. Prospero et al. (2002) and Bryant et al. (2007) describe Makgadikgadi pans as an important source for atmospheric mineral dust. Material was collected from three different 

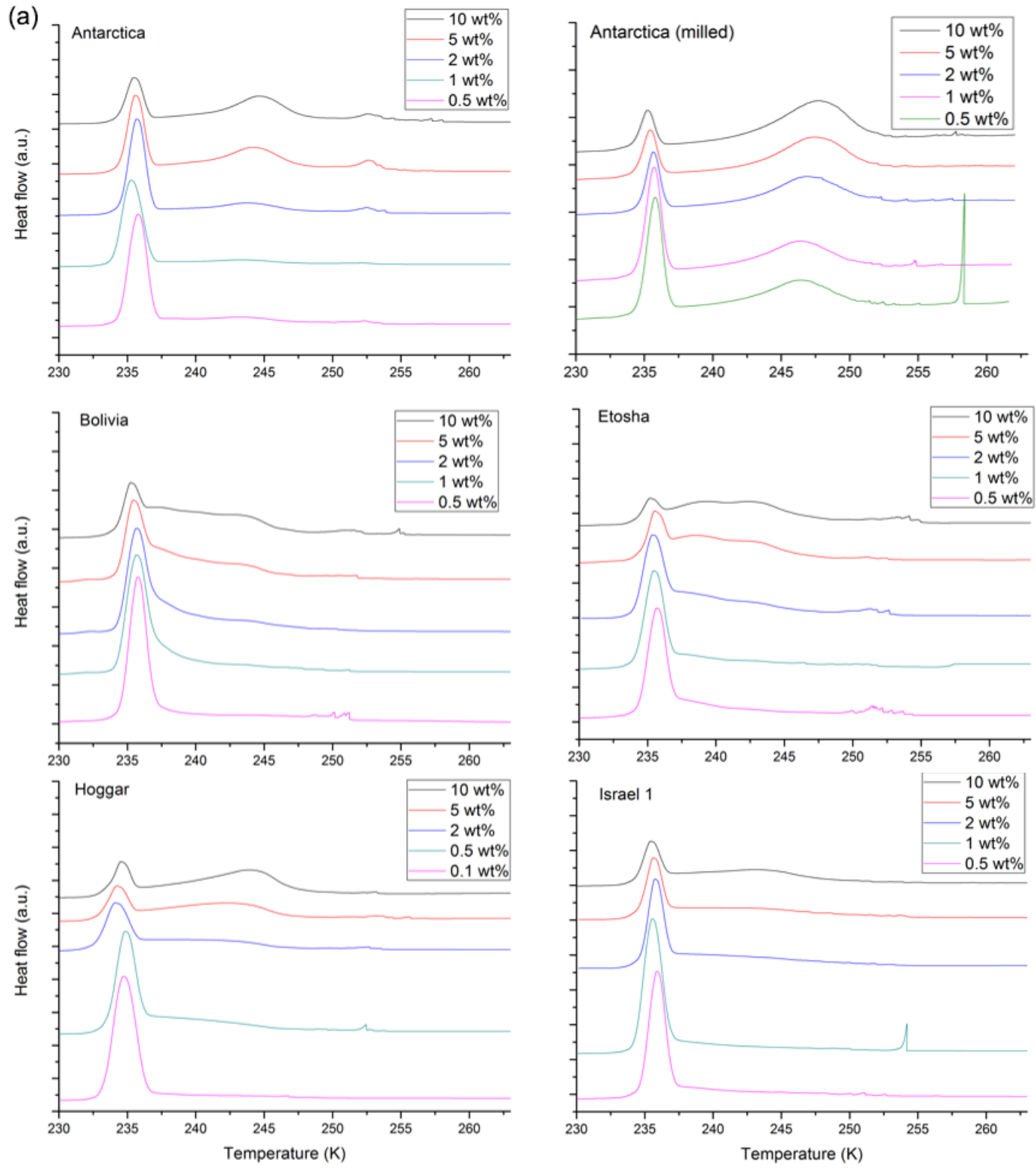

Figure 3.

places and analysed separately as samples indexed as A, B, and C. Makgadikgadi A was collected at $20.60^{\circ} \mathrm{S}$ and $25.22^{\circ} \mathrm{E}$ directly in the Ntwetwe pan. There was a light crust on the surface, which is probably salt, in accordance with the halite component detected in the XRD measurements. Makgadikgadi B was collected at $20.71^{\circ} \mathrm{S}$ and $25.21^{\circ} \mathrm{E}$ in the Ntwetwe pan, too. There was again a light crust on the surface and halite was also found in the XRD measurements. Makgadikgadi $C$ was collected at $21.01^{\circ} \mathrm{S}$ and $25.06^{\circ} \mathrm{E}$ at a southern branch of the Ntwetwe pan. The sample was collected next to a fence, where cattle were present. There was no crust.

8. The Oman dune sample was directly collected in the desert from dunes at $25.0995^{\circ} \mathrm{N}$ and $51.34^{\circ} \mathrm{E}$. Dunes consist mainly of coarse material, which was also reflected by the fact that a large amount of dune sand was necessary to gain small quantities of material consisting of particles smaller than $32 \mu \mathrm{m}$ in diameter. Nevertheless, Prospero et al. (2002) show strong dust events in this region.

9. The Qatar dune sample was directly collected in the desert from dunes at $25.10^{\circ} \mathrm{N}$ and $51.34^{\circ} \mathrm{E}$. This is also a region with strong dust events (Prospero et al., 2002). 

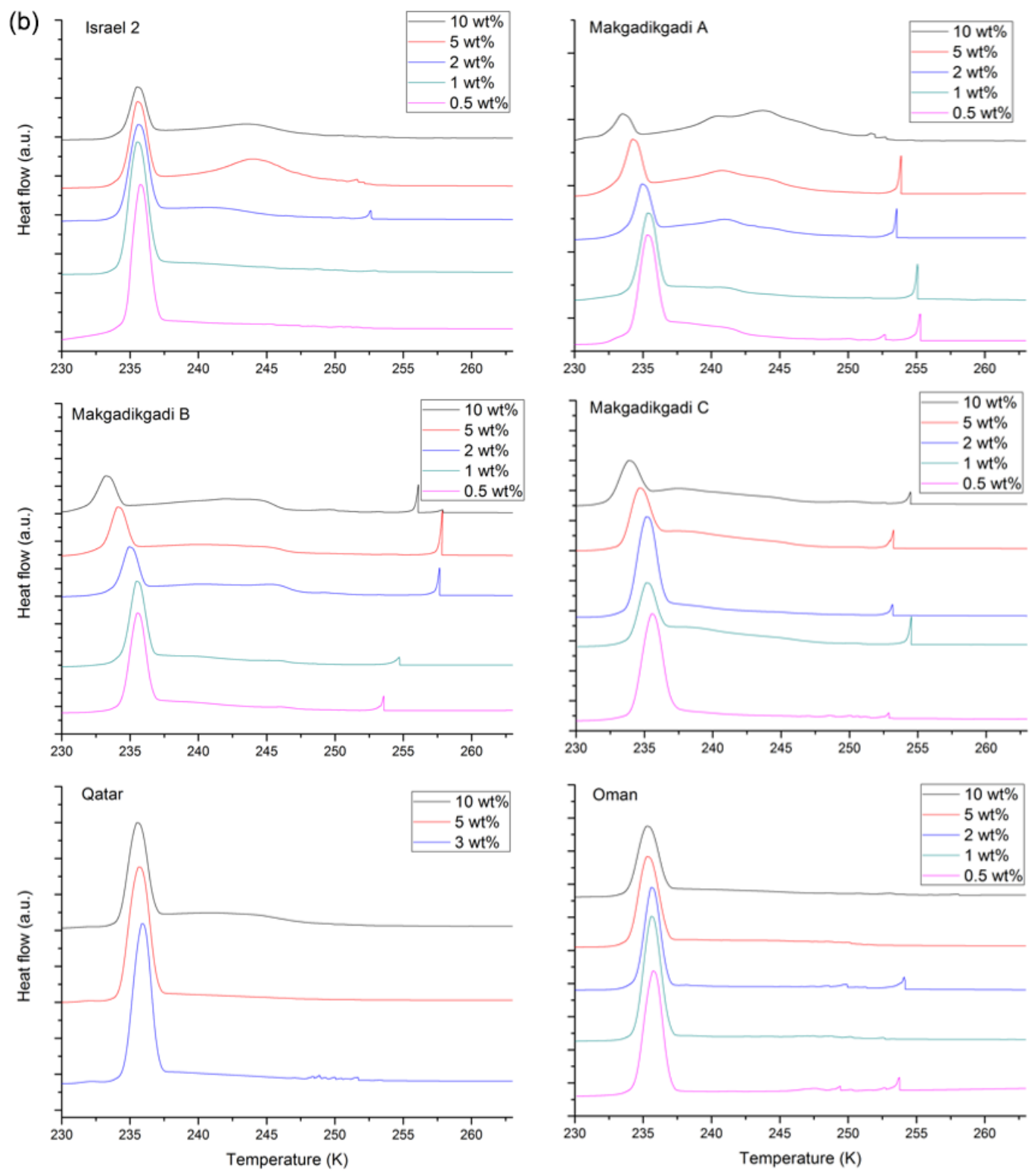

Figure 3. (a) DSC thermograms of natural dust samples: Antarctica, Antarctica (milled), Bolivia, Etosha, Hoggar and Israel 1. (b) DSC thermograms of natural dust samples: Israel 2, Makgadikgadi (A, B, and C), Qatar and Oman. Suspension concentrations are given in the legend.

\subsection{Minerals}

To correlate the freezing behaviour of natural dust samples with their mineralogical composition, reference minerals provided by the Institute of Geochemistry and Petrology of ETH Zurich were milled and investigated the same way as the natural dust samples.

\section{Results}

\subsection{Natural dust samples}

\subsubsection{Freezing experiments}

Figure $3 \mathrm{a}$ and $\mathrm{b}$ show the thermograms of the emulsion measurements of all natural dust samples for suspension concentrations ranging from 0.1 to $10 \mathrm{wt} \%$. The investigated natural dusts exhibit a homogeneous freezing peak with maximum at $235.0-235.5 \mathrm{~K}$ and heterogeneous freezing in the wide temperature range of $236-252 \mathrm{~K}$. In the thermograms 
Table 2. Evaluation of active particle fractions $\left(f_{\text {act }}\right)$ in natural dust samples evaluated for 2 wt $\%$ suspensions, with the exception of $\operatorname{ATD}(5 \mathrm{wt} \%) . D_{\mathrm{p} 1}$ : droplet diameter with on average 1 particle inside $(\mu \mathrm{m}) ; p_{\text {het }}$ : calculated heterogeneously frozen water volume frac-

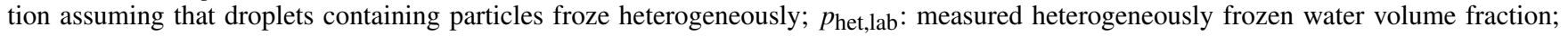
$f_{\text {act }}(0.5) / f_{\text {act }}(2)$ : ratio of $f_{\text {act }}$ determined for 0.5 and $2 \mathrm{wt} \%$ suspensions; $f_{\text {act }}(2) / f_{\text {act }}(10)$ : ratio of $f_{\text {act }}$ determined for 2 and $10 \mathrm{wt} \%$ suspensions.

\begin{tabular}{lcccccc}
\hline Sample & $D_{\mathrm{p} 1}$ & $p_{\text {het }}$ & $p_{\text {het }, \text { lab }}$ & $f_{\text {act }}$ & $f_{\text {act }}(0.5) / f_{\text {act }}(2)$ & $f_{\text {act }}(2) / f_{\text {act }}(10)$ \\
\hline Antarctica & 3.25 & 0.89 & 0.37 & 0.067 & 2.4 & 1.0 \\
Antarctica milled & 2.00 & 0.97 & 0.73 & 0.088 & 1.5 & 1.5 \\
ATD & 2.25 & 0.95 & 0.90 & 0.510 & - & - \\
Bolivia & 2.00 & 0.98 & 0.49 & 0.025 & 1.7 & 1.9 \\
Etosha & 5.50 & 0.59 & 0.33 & 0.320 & 0.8 & 1.3 \\
Hoggar & 2.75 & 0.91 & 0.43 & 0.063 & 2.7 & 1.0 \\
Israel 1 & 3.25 & 0.87 & 0.46 & 0.120 & 1.4 & 2.1 \\
Israel 2 & 3.75 & 0.80 & 0.37 & 0.140 & 1.8 & 3.1 \\
Makgadikgadi A & 3.25 & 0.86 & 0.62 & 0.230 & 1.6 & 3.8 \\
Makgadikgadi B & 3.00 & 0.89 & 0.53 & 0.120 & 1.8 & 1.1 \\
Makgadikgadi C & 2.75 & 0.91 & 0.31 & 0.037 & 2.7 & \\
\hline
\end{tabular}

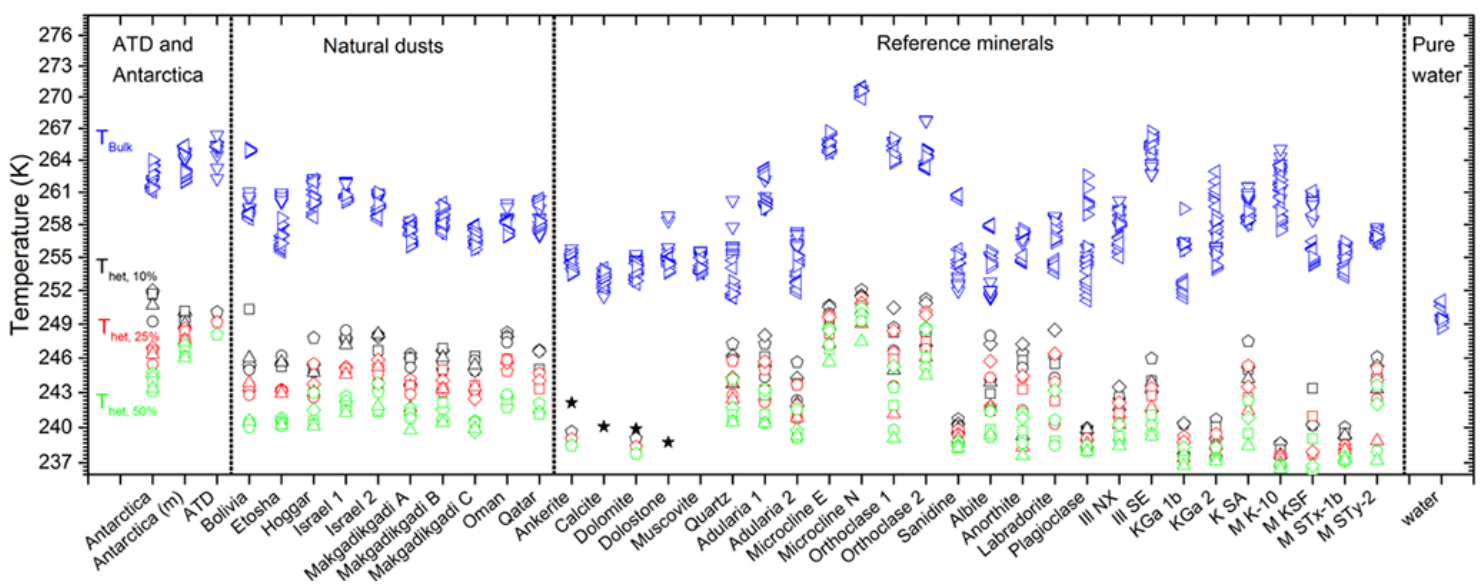

Figure 4. Overview of emulsion and bulk freezing temperatures of natural dusts and reference minerals determined from DSC experiments. Reference samples are from this study and from Pinti et al. (2012). Emulsion freezing experiments were carried out with suspension concentrations of $0.5 \mathrm{wt} \%$ (triangles), $1 \mathrm{wt} \%$ (circles), $2 \mathrm{wt} \%$ (squares), $5 \mathrm{wt} \%$ (diamonds), and $10 \mathrm{wt} \%$ (pentagons). Temperatures of $10 \%$ heterogeneously frozen water volume $\left(T_{\text {het }}, 10 \%\right), 25 \%$ heterogeneously frozen water volume $\left(T_{\text {het }}, 25 \%\right)$, and $50 \%$ heterogeneously frozen water volume $\left(T_{\text {het }}, 50 \%\right)$ are given by black, red, and green symbols, respectively. Black stars give the onset temperatures for minerals with a weak heterogeneous freezing signal. Blue symbols refer to bulk measurements carried out with a 5 wt $\%$ suspension. Different symbols refer to different bulk samples. On the far right, bulk measurements of pure water are shown for comparison, with freezing temperatures $<252.5 \mathrm{~K}$. Homogeneous freezing in emulsion samples occurs at $T<236.5 \mathrm{~K}$.

of the samples from Antarctica, Bolivia, Etosha and Makgadikgadi A, two or even three heterogeneous freezing peaks appear. The intensity of these peaks varies depending on the suspension concentration. Peaks at low temperatures prevail for low concentrations while with increasing concentration peaks at higher temperatures gain intensity because the number of INPs per droplet increases. The freezing behaviour of a droplet including more than one INP is controlled by the most potent one, which nucleates ice at the highest temperature. Therefore, less potent INPs are dominated by the most potent one at high concentrations. Table 2 shows the active particle fraction $\left(f_{\text {act }}\right)$ together with $p_{\text {het }}$ and $p_{\text {het, lab }}$, the calculated and measured heterogeneously frozen water volume fractions. These quantities have been determined according to Eqs. (6)-(8). In addition, Table 2 gives the estimated droplet diameter with an average of one particle inside $\left(D_{\mathrm{p} 1}\right)$ for $2 \mathrm{wt} \%$ suspension concentration, which is lowest for the Bolivia $(2.0 \mu \mathrm{m})$ and highest for the Etosha sample $(5.5 \mu \mathrm{m})$. The calculated number of dust particles per droplet depends on the measured number size distributions shown in Table 1, which have mode diameters between $216 \mathrm{~nm}$ (Bolivia sample) and $479 \mathrm{~nm}$ (Israel 2 sample). For all dust sam-

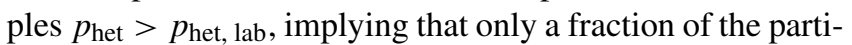
cles present in the natural dusts are active as INPs. The active 
particle fraction $f_{\text {act }}$ is lowest for the Bolivia sample (0.025) and highest for the Etosha sample (0.32). There are considerable uncertainties associated with $f_{\text {act }}$ that are discussed in detail in Appendix A. Based on this uncertainty evaluation $f_{\text {act }}$ may be up to 5.8 times larger and 2.3 times smaller than the values given in Table 2. Due to the fact that not enough material of the Oman and Qatar samples was available for particle size distribution measurements, no evaluation was possible for these samples.

A summary of DSC measurements of all dusts is given in Fig. 4 together with results for the reference samples, which will be discussed later. Figure 4 displays the evaluation of the heterogeneous freezing temperatures of the natural dust samples with respect to $10 \%\left(T_{\text {het, } 10 \%}\right), 25 \%$ ( $\left.T_{\text {het, } 25 \%}\right)$, and $50 \%\left(T_{\text {het }, 50 \%}\right)$ water volume frozen heterogeneously. This method of representation was chosen to obtain characteristic heterogeneous freezing temperatures to compare the different samples. For all samples, an increase of the characteristic temperatures with increasing suspension concentration can be observed. Blue symbols show onsets of heterogeneous freezing for bulk samples. With each sample, a series of freezing cycles were run which are all designated by the same symbol in Fig. 4. Bulk experiments run with different portions of the same stock suspensions are represented by different symbols.

The natural dust samples all show surprisingly similar freezing temperatures for emulsion freezing, with the notable exceptions of Antarctica and ATD. Indeed, a 10\% heterogeneously frozen fraction for natural dust samples (except Antarctica and ATD) is realized between 244 and $250 \mathrm{~K}$. The $25 \%$ heterogeneously frozen fraction is between 242 and $246 \mathrm{~K}$, and the $50 \%$ heterogeneously frozen fraction is between 239 and $244 \mathrm{~K}$. Also bulk freezing (with $5 \mathrm{wt} \%$ suspension concentration) occurs in a compact temperature range between 255 and $262 \mathrm{~K}$ (except for ATD, the Antarctica sample, and one sample from Bolivia).

For ATD in emulsions, the $10 \%$ heterogeneously frozen fraction is at $250.5 \mathrm{~K}$, the $25 \%$ heterogeneously frozen fraction is at $249.5 \mathrm{~K}$, and the $50 \%$ heterogeneously frozen fraction is at $248 \mathrm{~K}$. Bulk freezing occurs at comparatively high temperatures between 262 and $266 \mathrm{~K}$. For the Antarctica sample, the $10 \%$ heterogeneously frozen fraction is between 249 and $252 \mathrm{~K}, 25 \%$ between 245 and $248 \mathrm{~K}$, and $50 \%$ between 243 and $245 \mathrm{~K}$. Bulk freezing occurs between 261 and $264 \mathrm{~K}$.

\subsubsection{Mineralogical composition}

Table 3 lists the minerals identified in the natural dust samples by the Rietveld refinement of the X-ray diffractograms. We consider the mineralogical composition determined by XRD diffraction as accurate within $\pm 15 \%$ (see Appendix B). Minor components might remain undetected.

The Antarctica sample has high shares of K-feldspars and $(\mathrm{Na}, \mathrm{Ca}$ )-feldspars, but contains also muscovite and quartz. The sample from Bolivia has high shares of clay minerals (kaolinite, smectite) but contains additional calcite $\left(\mathrm{CaCO}_{3}\right)$, quartz, and plagioclase. The Etosha sample mainly consists of carbonates, namely calcite $\left(\mathrm{CaCO}_{3}\right)$, dolomite $\left(\mathrm{CaMg}\left(\mathrm{CO}_{3}\right)_{2}\right)$, and ankerite $\left(\mathrm{Ca}(\mathrm{Fe}, \mathrm{Mg}, \mathrm{Mn})\left(\mathrm{CO}_{3}\right)_{2}\right)$. The samples from Israel contain calcite as the main component with over $60 \%$ together with minor fractions of quartz, ankerite, the clay minerals illite and smectite (montmorillonite), muscovite (mica), and the feldspars sanidine and plagioclase. Samples from Makgadikgadi show quite diverse mineralogical compositions containing calcite, muscovite, quartz, and clay minerals but hardly any feldspars. The dune samples from Oman and Qatar mainly consist of quartz, calcite, and the ( $\mathrm{Na}, \mathrm{Ca}$ )-feldspar plagioclase. Finally, the sample from Qatar also contains dolomite and the K-feldspar microcline, and the one of Oman contains the K-feldspar sanidine.

\subsection{Reference minerals}

The analysed reference minerals can be classified in four groups, as shown in Table 1. The first group consists of the most frequently found minerals in the natural dust samples, namely quartz, muscovite, and the carbonates calcite, dolomite/dolostone, and ankerite. The second group are $\mathrm{K}-$ feldspars (adularia, microcline, orthoclase, and sanidine), which proved to have a high ice nucleation efficiency (Atkinson et al., 2013; Emersic et al., 2015; Zolles et al., 2015; Harrison et al., 2016; Peckhaus et al., 2016). The third group consists of ( $\mathrm{Na}, \mathrm{Ca}$ )-feldspars (anorthite, labradorite, albite (pericline), and plagioclase, not further specified), which have been reported to be quite efficient as INPs (Atkinson et al., 2013; Augustin-Bauditz et al., 2014; Zolles et al., 2015; Peckhaus et al., 2016), though less efficient than Kfeldspars. The fourth group are clay minerals: DSC freezing experiments of illite, kaolinite, and montmorillonite (member of the smectite group) have been performed by Pinti et al. (2012) and can be used here as references for clay minerals. Most of the other minerals that could be identified in the natural dust samples are water soluble and therefore not relevant for immersion freezing.

\subsubsection{Mineralogical composition}

Table 4 lists the mineralogical composition of the reference samples identified by the Rietveld refinement of the $\mathrm{X}$-ray diffractograms. In most cases, the Rietveld analysis yields compositions in agreement with the identification of the stones by the Institute of Geochemistry and Petrology of ETH Zurich (see Sect. 2). Mineralogically pure or almost pure samples of the assigned composition proved to be calcite, dolomite, muscovite, quartz, sanidine, and plagioclase. However, for the K-feldspars adularia and orthoclase, the composition assigned by X-ray diffraction was different from the geological identification of stones. The adu- 
Table 3. Mineralogical composition of natural dust samples in wt \% derived from the Rietveld analysis of the X-ray diffraction (XRD) patterns. The abbreviations stand for cal: calcite; dol: dolomite; mus: muscovite; qu: quartz; adu: adularia; mic: microcline; ort: orthoclase; san: sanidine; pla: plagioclase; ill: illite; ka: kaolinite; sm: smectite (montmorillonite).

\begin{tabular}{|c|c|c|c|c|c|c|c|c|c|c|c|c|c|}
\hline Sample & $\mathrm{cal}$ & dol & mus & $\mathrm{qu}$ & adu & mic & ort & san & pla & ill & $\mathrm{ka}$ & $\mathrm{sm}$ & Others \\
\hline Antarctica & & & 18 & 24 & & 15 & 4 & & 29 & & & & biotite 2 ; chlorite 3 ; epidote 4 \\
\hline ATD & 1 & & & 23 & & 29 & 1 & 6 & 12 & 3 & $<1$ & 25 & ankerite $<1$; tremolite $<1$ \\
\hline Bolivia & 17 & & & 4 & & & & & 22 & & 4 & 50 & wollastonite 3 \\
\hline Etosha & 29 & 27 & 10 & 1 & & & & & & & & 1 & $\begin{array}{l}\text { analcime }<1 ; \text { ankerite } 23 \\
\text { chabazite }<1 ; \text { halite }<1 ; \\
\text { kyanite } 2 ; \text { sepiolite } 4 ; \text { tridymite }<1\end{array}$ \\
\hline Hoggar & & & & 13 & & & & 10 & 13 & 4 & 6 & 48 & $\begin{array}{l}\text { biotite } 4 \text {; brookite }<1 \text {; } \\
\text { fluorapatite }<1 \text {; hematite }<1\end{array}$ \\
\hline Israel 1 & 68 & & 6 & 8 & & & & 2 & 2 & $<1$ & & 6 & ankerite 8 \\
\hline Israel 2 & 65 & & 2 & 10 & & & & 2 & 3 & 3 & & 7 & $\begin{array}{l}\text { ankerite } 5 \text {; fluorapatite } 2 \text {; } \\
\text { magnesite }<1\end{array}$ \\
\hline Makgadikgadi A & 25 & & 21 & 4 & 3 & & & & 5 & & & 23 & $\begin{array}{l}\text { anatase }<1 \text {; halite } 2 \text {; } \\
\text { szomolnokite } 1 \text {; trona } 14 ; \\
\text { virgilite }<1\end{array}$ \\
\hline Makgadikgadi B & 3 & & 1 & 1 & & & & $<1$ & & & 76 & 6 & $\begin{array}{l}\text { cristobalite }<1 \text {; halite } 2 \\
\text { thenardite } 10\end{array}$ \\
\hline Makgadikgadi C & 43 & & & 3 & 3 & & & & & & 10 & 20 & $\begin{array}{l}\text { barite }<1 \text {; feruvite } 1 \text {; halite } 3 \text {; } \\
\text { lepidolite } 3 \text {; nontronite } 5 \text {; } \\
\text { sulfur alpha } 4 \text {; thenardite } 6\end{array}$ \\
\hline Oman & 29 & & & 26 & & & & 5 & 12 & & & & chlorite 7 \\
\hline Qatar & 31 & 21 & & 12 & & 4 & & & 8 & & & 13 & $\begin{array}{l}\text { chlorite } 2 \text {; diopside } 1 \text {; } \\
\text { ferrite magnesion }<1 \text {; hematite } 2 \text {; } \\
\text { hornblende } 3\end{array}$ \\
\hline
\end{tabular}

Table 4. Mineralogical composition of reference samples in wt \%. The abbreviations stand for cal: calcite; dol: dolomite; mus: muscovite; qu: quartz; adu: adularia; mic: microcline; ort: orthoclase; san: sanidine; pla: plagioclase; ill: illite; ka: kaolinite; sm: smectite (montmorillonite).

\begin{tabular}{|c|c|c|c|c|c|c|c|c|c|c|c|c|}
\hline Sample & $\mathrm{cal}$ & dol & mus & qu & adu & mic & ort & san & pla & ill & ka $\quad \mathrm{sm}$ & Others \\
\hline Ankerite & 99 & & & & & & & & & & & ankerite $<1$ \\
\hline Calcite & 100 & & & & & & & & & & & \\
\hline Dolomite & & 100 & & & & & & & & & & \\
\hline Dolostone & & 100 & & & & & & & & & & \\
\hline Muscovite & & & 100 & & & & & & & & & \\
\hline Quartz & & & & 100 & & & & & & & & tungsten carbide $<1$ \\
\hline Adularia 1 & & & & & & & & 100 & & & & \\
\hline Adularia 2 & & & & & 100 & & & & & & & \\
\hline Microcline E & & & & & & 90 & & & 10 & & & \\
\hline Microcline N & & & & $<1$ & & 77 & & & 22 & & & langanite $<1$ \\
\hline Orthoclase 1 & & & & 4 & & & & 77 & 15 & 4 & & \\
\hline Orthoclase 2 & & & & 2 & & 78 & & & 13 & & & epidote 6 ; chlorite 2 \\
\hline Sanidine & & & & & & & & 100 & & & & \\
\hline Albite & & & & 16 & & & & & 84 & & & \\
\hline Anorthite & & 1 & 8 & 12 & & & & & 59 & & 5 & $\begin{array}{l}\text { azurite }<1 \text {; feruvite } 2 \text {; prehnite } 5 \text {; } \\
\text { trona } 2 \text {; zoisite } 7\end{array}$ \\
\hline Labradorite & & & & & & & & & 100 & & & \\
\hline Plagioclase & & & & & & & & & 100 & & & \\
\hline
\end{tabular}

laria stone proved to be $100 \%$ sanidine, and the orthoclase stone consisted mostly of sanidine $(77 \%)$ with no share of orthoclase. Sanidine is the high temperature polymorph of orthoclase, i.e. also a K-feldspar. We therefore obtained a second stone of adularia and of orthoclase, which we labelled adularia 2 and orthoclase 2 . Indeed, adularia 2 proved to be 

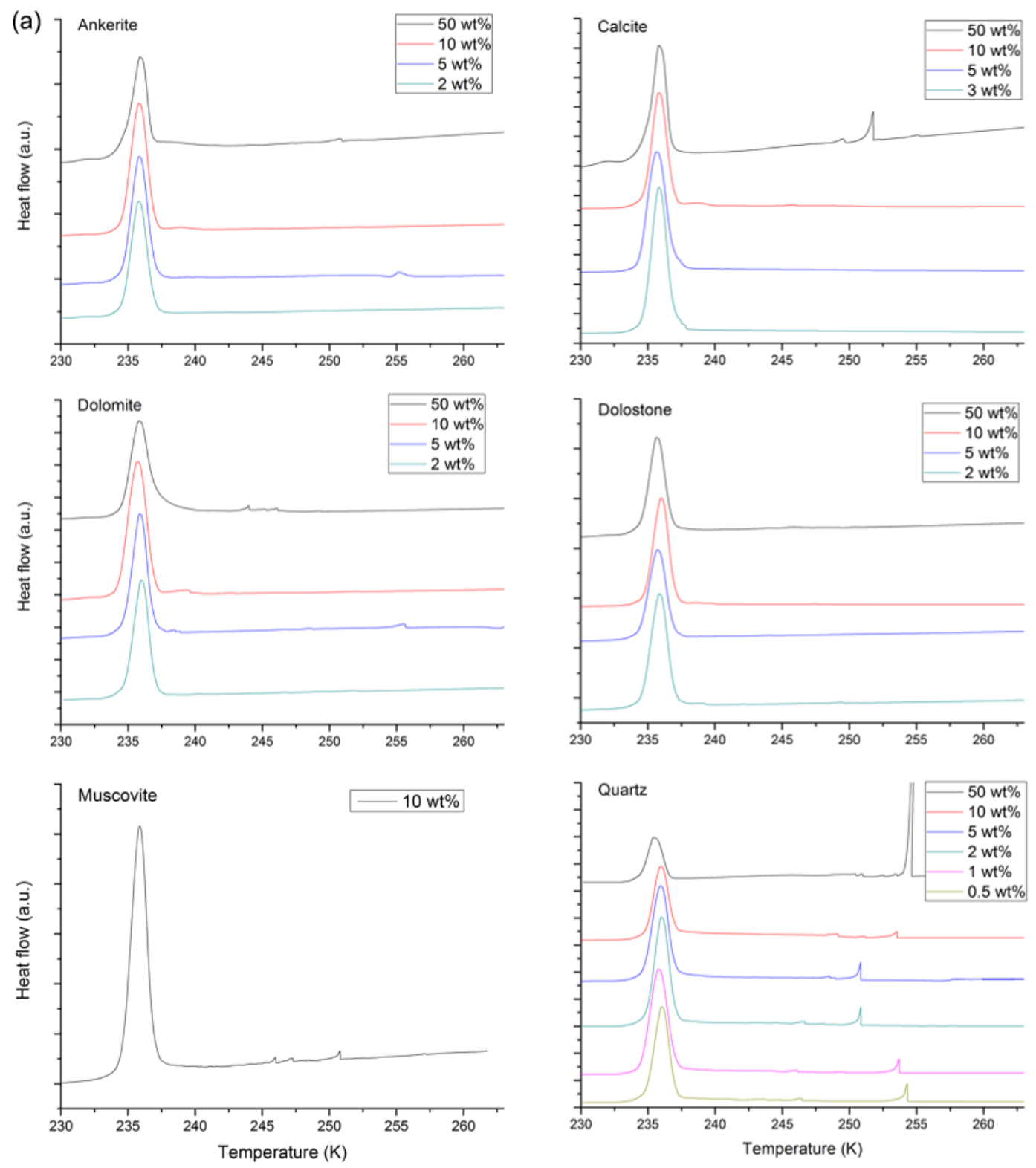

Figure 5.

$100 \%$ adularia; however, orthoclase 2 contained $78 \%$ of the $\mathrm{K}$-feldspar microcline with no share of orthoclase. Therefore, we do not have a reference for orthoclase. Two stones of ankerite $\left(\mathrm{Ca}(\mathrm{Fe}, \mathrm{Mg}, \mathrm{Mn})\left(\mathrm{CO}_{3}\right)_{2}\right.$, trigonal) were tested. For the first stone, the Rietveld refinement yielded $99.5 \%$ calcite $\left(\mathrm{CaCO}_{3}\right.$, trigonal $)$ and only $0.5 \%$ ankerite; the second one consisted only of calcite with no ankerite present at all. The mineralogical similarity between ankerite and calcite might be the reason why ankerite was mistaken as calcite. Dolostone is a sedimentary rock that is chiefly composed of the mineral dolomite $\left(\mathrm{CaMg}\left(\mathrm{CO}_{3}\right)_{2}\right)$. Rietveld analysis of the X-ray diffractogram identified it as $100 \%$ dolomite. The microcline stone from Elba (microcline E) contained $90 \%$

microcline and the one from Namibia (microcline N) $77 \%$ microcline, both with plagioclase as a minor component. Albite (pericline), anorthite, and labradorite are all members of the plagioclase ( $\mathrm{Na}, \mathrm{Ca}$ )-feldspar solid solution series with triclinic crystal symmetry. All of them were identified as plagioclase by our XRD analysis. The plagioclase and labradorite samples were identified as pure plagioclase; for albite (pericline) minor shares of quartz (16\%) were also found. For the anorthite sample, in addition to plagioclase as the main component (59\%), $12 \%$ quartz, $8 \%$ muscovite, and $5 \%$ kaolinite were identified as the most abundant minor components. It is not clear whether the Rietveld refinement 

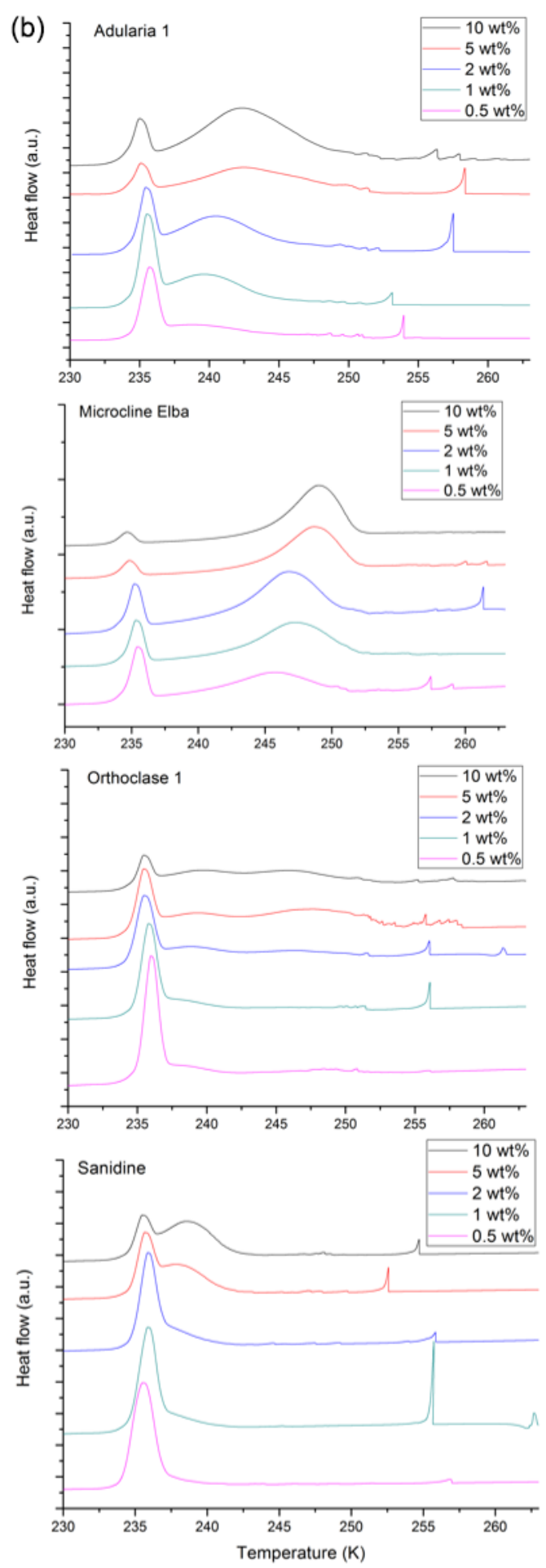

Figure 5.

was not able to discriminate between the different $(\mathrm{Na}, \mathrm{Ca})$ feldspars and assigned them all as plagioclase.
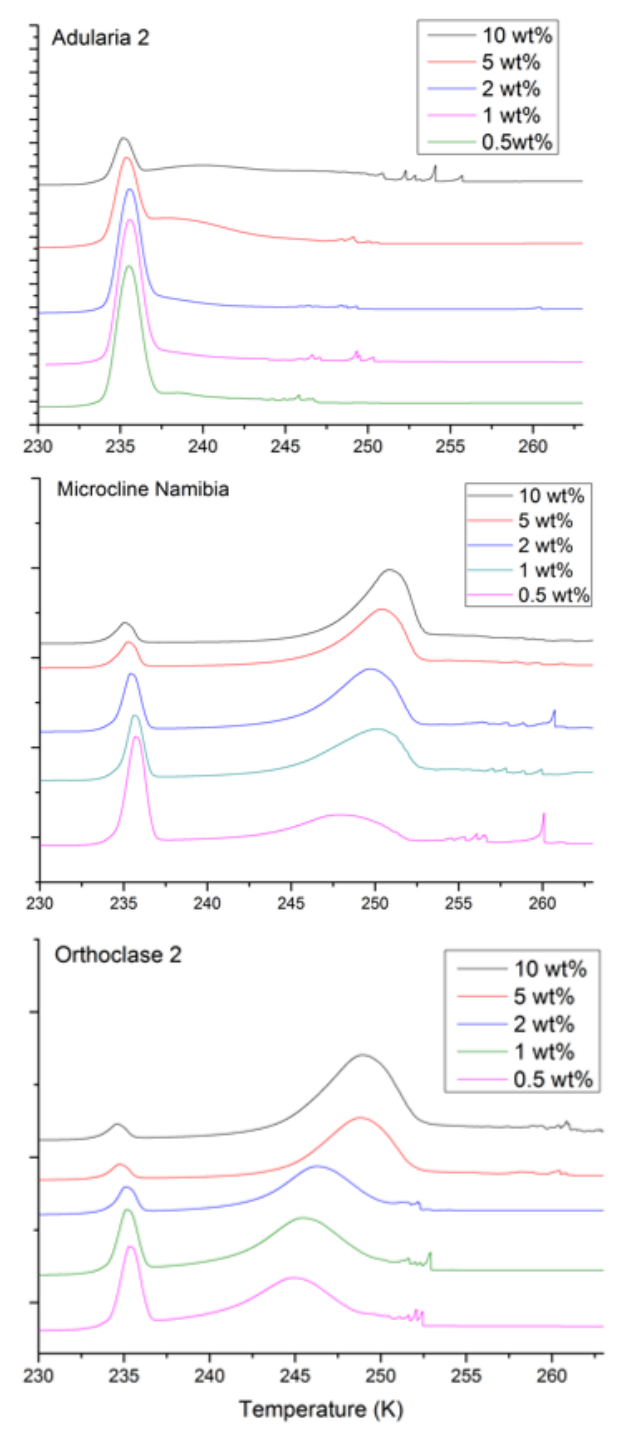

\subsubsection{Freezing experiments}

DSC thermograms of the reference minerals are shown in Fig. 5a-c for concentrations ranging from 0.5 to $10 \mathrm{wt} \%$. A summary plot is given in Fig. 4. Table 5 shows the active par- 

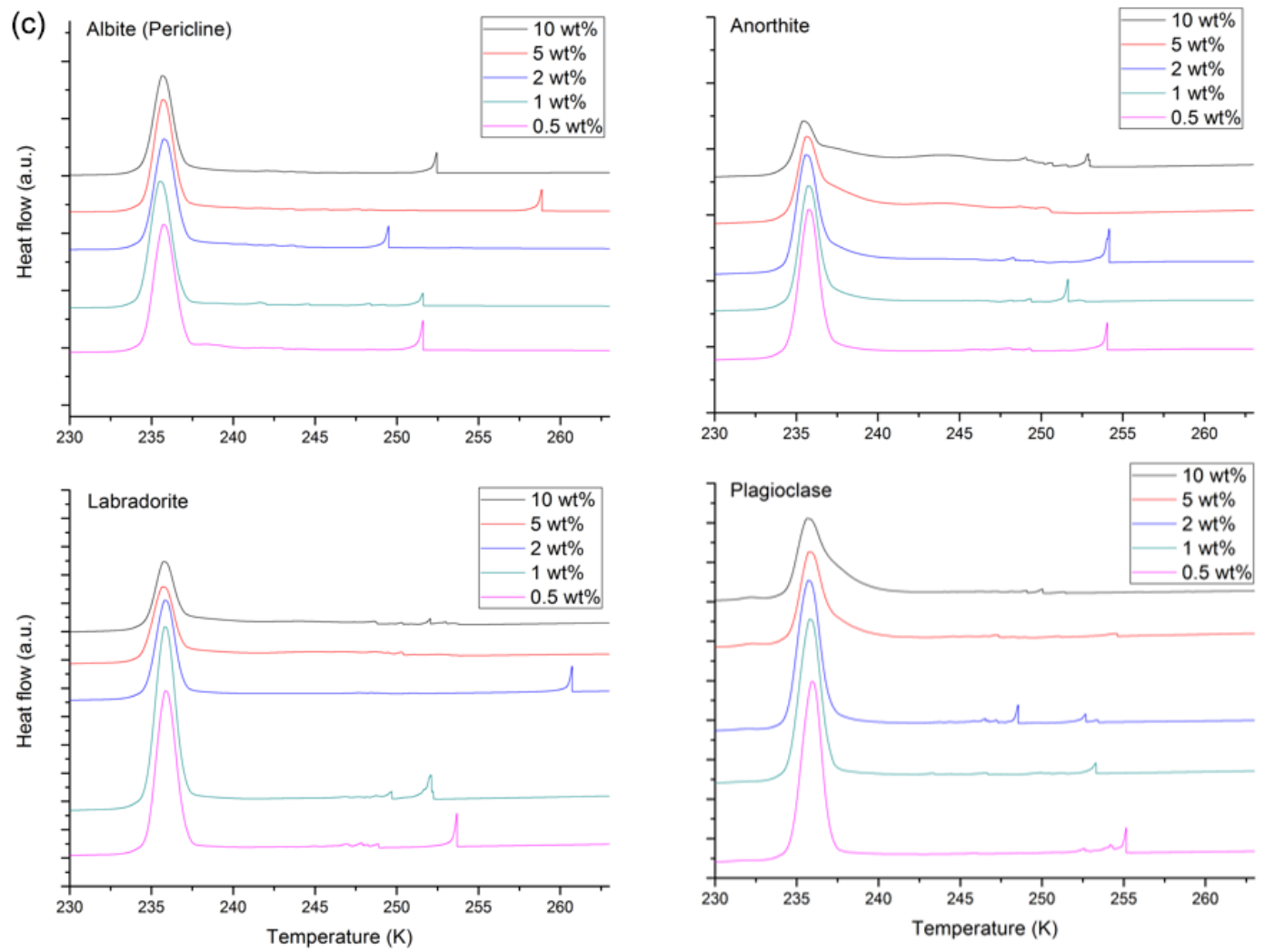

Figure 5. (a) DSC thermograms of frequently found minerals: ankerite, calcite, dolomite, dolostone, muscovite, and quartz. Suspension concentrations are given in the legend. (b) DSC thermograms of K-feldspars: adularia 1 and 2, microcline E, microcline N, orthoclase 1 and 2, sanidine. Suspension concentrations are given in the legend. (c) DSC thermograms of (Na, Ca)-feldspars: albite (pericline), anorthite, labradorite, plagioclase. Suspension concentrations are given in the legend.

ticle fraction $f_{\text {act }}$. For the samples of calcite, dolomite, dolostone, and ankerite, it was hardly possible to evaluate the 10 , 25 , and $50 \%$ heterogeneously frozen fractions because the heterogeneous freezing signal was so weak. These minerals were therefore also measured in $50 \mathrm{wt} \%$ suspensions. Onset temperatures were evaluated as well and designated by black stars in Fig. 4. We refer to the reference minerals with the identification given by the Institute of Geochemistry and Petrology even if the XRD analysis revealed a different composition.

The DSC thermograms of the emulsion freezing experiments for the minerals ankerite, calcite, dolomite, dolostone, muscovite, and quartz are shown in Fig. 5a. Note that the dolostone sample was identified as $100 \%$ dolomite by XRD. The $10 \%$ heterogeneously frozen fractions are all below $240 \mathrm{~K}$. These samples also exhibit low bulk freezing temperatures between 251 and $260 \mathrm{~K}$ with most freezing events around $254 \mathrm{~K}$. Table 5 shows that less than $1 \%$ of the particles were active as INPs. Low ice nucleation activity of calcite is in accordance with Atkinson et al. (2013). The DSC thermogram of the ankerite sample is very similar as the one of calcite, in agreement with the XRD identification of this sample as calcite. Quartz showed a weak heterogeneous sig- nal at $244-247 \mathrm{~K}$ for $10 \%$ heterogeneously frozen fraction, at $243-246 \mathrm{~K}$ for $25 \%$ heterogeneously frozen fraction, and at $240-245 \mathrm{~K}$ for $50 \%$ heterogeneously frozen fraction but with a low active particle fraction of $f_{\text {act }}=0.01$. These results are in qualitative agreement with Atkinson et al. (2013), who found heterogeneous freezing up to $247 \mathrm{~K}$. Zolles et al. (2015) found considerably different nucleation efficiencies for three different pure alpha quartz samples with median freezing temperatures $T_{50}$ of 235,239 , and $249 \mathrm{~K}$. The reason for these large differences might be due to different numbers of defects present on the surface of the particles (Zolles et al., 2015). On the other hand, Boose et al. (2016) conjectured an important role of quartz for the ice nucleation activity of natural desert dusts by correlating mineralogical composition and ice nucleation activity of 15 natural desert dust samples. For the muscovite (mica) sample, no heterogeneous freezing was observed in emulsion experiments. This is consistent with Atkinson et al. (2013) who found hardly any ice nucleation activity for their mica sample.

Figure $5 \mathrm{~b}$ shows the thermograms for the emulsion experiments for all examined $\mathrm{K}$-feldspars for concentrations ranging from 0.5 to $10 \mathrm{wt} \%$. Interestingly, there are significant differences between their ice nucleation activities. Mi- 
Table 5. Evaluation of active particle fractions $\left(f_{\text {act }}\right)$ of natural dust samples applied to $2 \mathrm{wt} \%$ suspensions, with the exceptions of ankerite $(50 \mathrm{wt} \%)$, dolomite $(50 \mathrm{wt} \%)$, and muscovite $(10 \mathrm{wt} \%) . D_{\mathrm{p} 1}$ : droplet diameter with on average 1 particle inside $(\mu \mathrm{m}) ; p_{\text {het }}:$ calculated

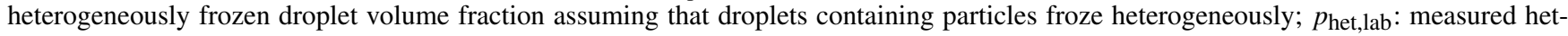
erogeneously frozen water volume fraction; $f_{\text {act }}(0.5) / f_{\text {act }}(2)$ : ratio of $f_{\text {act }}$ determined for 0.5 and 2 wt $\%$ suspensions; $f_{\text {act }}(2) / f_{\text {act }}(10)$ : ratio of $f_{\text {act }}$ determined for 2 and $10 \mathrm{wt} \%$ suspensions.

\begin{tabular}{lllllll}
\hline Sample & $D_{\mathrm{p} 1}$ & $p_{\text {het }}$ & $p_{\text {het,lab }}$ & $f_{\text {act }}$ & $f_{\text {act }}(0.5) / f_{\text {act }}(2)$ & $f_{\text {act }}(2) / f_{\text {act }}(10)$ \\
\hline Ankerite & 1 & 1.00 & 0.15 & 0.0007 & - & - \\
Calcite & 2.25 & 0.96 & - & - & - & - \\
Dolomite & 0.75 & 1.00 & 0.13 & 0.0004 & - & - \\
Dolostone & 2.75 & 0.90 & - & - & - & - \\
Muscovite & 1.5 & 0.99 & - & - & - & - \\
Quartz & 2.75 & 0.91 & 0.12 & 0.012 & 2.67 & 1.5 \\
Adularia 1 & 2.75 & 0.92 & 0.72 & 0.23 & 1.1 & 1.9 \\
Adularia 2 & 2 & 0.97 & 0.20 & 0.008 & 2.5 & 0.3 \\
Microcline E & 3.25 & 0.88 & 0.82 & 0.64 & 1.5 & 1.5 \\
Microcline N & 3.25 & 0.87 & 0.78 & 0.54 & 1.2 & 1.9 \\
Orthoclase 1 & 3.25 & 0.87 & 0.54 & 0.17 & 0.6 & 1.2 \\
Orthoclase 2 & 2.25 & 0.95 & 0.88 & 0.40 & 1.4 & 1.5 \\
Sanidine & 2.75 & 0.90 & 0.23 & 0.030 & 0.9 & 0.6 \\
Albite & 3.5 & 0.84 & 0.11 & 0.022 & 4.1 & 4.1 \\
Anorthite & 2.75 & 0.93 & 0.27 & 0.025 & 0.8 & 0.7 \\
Labradorite & 3.75 & 0.82 & 0.045 & 0.009 & - & 0.45 \\
Plagioclase & 3 & 0.89 & 0.049 & 0.0061 & - & 0.7 \\
Illite NX & 3.25 & 0.87 & 0.48 & 0.12 & 1.9 & 1.4 \\
Illite SE & 2.75 & 0.93 & 0.69 & 0.18 & - & - \\
KGa-1b & 2.5 & 0.93 & 0.37 & 0.041 & 2 & 0.4 \\
KGa-2 & 2.75 & 0.91 & 0.53 & 0.11 & 1.8 & 1 \\
K-SA & 3.75 & 0.82 & 0.4 & 0.13 & 0.4 & 1.9 \\
M K-10 & 3.25 & 0.86 & 0.32 & 0.067 & 0.6 & 1.4 \\
M KSF & 4.25 & 0.76 & 0.066 & 0.022 & - & - \\
M STx-1b & 2.75 & 0.92 & 0.52 & 0.089 & 0.7 & 1.4 \\
M SWy-2 & 2.75 & 0.93 & 0.82 & 0.40 & 2.3 & \\
\hline
\end{tabular}

crocline $\mathrm{N}$ is the most effective in emulsions as well as in bulk freezing experiments. It showed $10 \%$ heterogeneously frozen fractions at $250-253 \mathrm{~K}, 25 \%$ at $249-252 \mathrm{~K}$, and $50 \%$ at $248-251 \mathrm{~K}$. Bulk freezing occurred above $270 \mathrm{~K}$, which is exceptionally high compared with all other samples. Microcline $\mathrm{E}$ showed $10 \%$ heterogeneously frozen fractions at $249-252 \mathrm{~K}, 25 \%$ at $248-251 \mathrm{~K}$, and $50 \%$ at $246-249 \mathrm{~K}$. Bulk freezing occurred between 265 and $268 \mathrm{~K}$. The microclines had also high active particle fractions of $f_{\text {act }}=$ 0.54 (microcline $\mathrm{N}$ ) and 0.64 (microcline $\mathrm{E}$ ). The orthoclase 2 sample proved to be effective at nucleating ice with $f_{\text {act }}=0.4$, in accordance with its XRD analysis which identified it as $78 \%$ microcline with a minor share of plagioclase $(13 \%)$. The $10 \%$ heterogeneously frozen fraction occurred at $247-251 \mathrm{~K}, 25 \%$ at $246-250 \mathrm{~K}, 50 \%$ at $244.5-$ $248.5 \mathrm{~K}$, and bulk freezing at $263-268 \mathrm{~K}$. The sanidine sample proved to be much worse at nucleating ice than the microclines with heterogeneously frozen fractions of $10 \%$ below $241 \mathrm{~K}$. Bulk freezing occurred between 252 and $256 \mathrm{~K}$ and $f_{\text {act }}$ was only 0.03 . Our XRD analysis showed that adularia 1 consists of $100 \%$ sanidine. Nevertheless, the DSC ther- mogram is different from the one of the sanidine sample. Adularia 1 was superior at nucleating ice with $f_{\text {act }}=0.23$ and $10 \%$ heterogeneously frozen fraction up to $248 \mathrm{~K}$. Orthoclase 1 contains sanidine as the major component $(77 \%)$ and plagioclase (15\%), with quartz and illite (both $4 \%$ ) as minor components. The active particle fraction is higher than the one of the sanidine reference sample. DSC thermograms of the orthoclase 1 sample show two peaks. The one at lower temperatures prevails at lower suspension concentration, the one at higher temperatures becomes dominant at $5-10 \mathrm{wt} \%$ suspension concentration. Harrison et al. (2016) have recently performed freezing experiments with microliter droplets of aqueous suspensions of a ground sanidine sample. The observed freezing temperatures indicated a similarly high ice nucleation activity for this sanidine sample as for microclines. The mineralogical composition was investigated by Rietveld refinement of powder XRD patterns confirming sanidine as the dominant feldspar phase, however, without specifying minor components. Considering the high number of particles present in the microliter droplets, the results are not directly applicable to the freezing of emulsion 
droplets containing only one or a few particles. Nevertheless, we note a quite large variability in ice nucleation activity between sanidine samples, which does not seem to correlate with the mineralogical composition. Based on the emulsion experiments with DSC, we consider sanidine as ice nucleation active but compared with microcline only at lower temperatures. Adularia 2, which was indeed adularia based on the XRD analysis, exhibited 10, 25, and 50\% heterogeneously frozen fractions below $245.7 \mathrm{~K}$ and bulk freezing at $252-258 \mathrm{~K}$. The active particle fraction was 0.008 .

Figure $5 \mathrm{c}$ shows the thermograms of the emulsion experiments for all examined $(\mathrm{Na}, \mathrm{Ca})$-feldspars for concentrations ranging from 0.5 to $10 \mathrm{wt} \%$. The plagioclase sample shows low freezing temperatures (below $240 \mathrm{~K}$ ) for emulsion experiments and a strong scattering of bulk freezing temperatures from quite low $(251 \mathrm{~K})$ up to quite high $(263 \mathrm{~K})$. The albite (pericline) and the labradorite samples show similarly low freezing efficiencies as the plagioclase sample. This is in accordance with our XRD analysis, which found $100 \%$ plagioclase in the labradorite sample and $84 \%$ in the albite (pericline) sample, with the rest consisting of quartz. Harrison et al. (2016) investigated three albite samples yielding very different ice nucleation activities. One of them showed similarly high freezing temperatures as the microcline samples but lost its activity over time while suspended in water. The other samples showed distinctly lower freezing temperatures than the microclines but slightly higher ones than the plagioclase samples that they also investigated. For the anorthite sample, in addition to plagioclase as the main component (59\%), $12 \%$ quartz, $8 \%$ muscovite, and $5 \%$ kaolinite were identified as most abundant minor components. These minor components can explain the ice nucleation activity reaching a higher temperature compared with the other ( $\mathrm{Na}, \mathrm{Ca})$ feldspar samples only partly. These measurements confirm the findings of Atkinson et al. (2013) that ( $\mathrm{Na}, \mathrm{Ca}$ )-feldspars nucleate ice at lower temperature than K-feldspars. Compared with the (Na, Ca)-feldspars, all K-feldspars proved to nucleate ice at warmer temperatures. Nevertheless, the differences between them are significant with microcline being superior to the others. Therefore, it is not sufficient to discriminate just between $\mathrm{K}$-feldspars and $(\mathrm{Na}, \mathrm{Ca})$-feldspars but the specific crystal structure of the feldspars has to be considered as well.

Clay minerals have proven to nucleate ice efficiently at $T<246 \mathrm{~K}$ (Pinti et al., 2012). In Fig. 4 and Table 5 the values for the clay minerals measured by Pinti et al. (2012) are also given. The DSC thermograms shown in Pinti et al. (2012) were re-evaluated using the procedures outlined in Sect. 3 to obtain consistency with the new data presented in this study. The heterogeneously frozen fractions reported here are the sum of the heterogeneous signals without differentiating between standard and special peaks as was done in Pinti et al. (2012). Four different samples of montmorillonite have been investigated by Pinti et al. (2012): M KSF and M K10 from Sigma-Aldrich, and STx-1b and SWy-2 from the
Clay Mineral Society (CMS). None of these samples is mineralogically pure (Atkinson et al., 2013). M KSF and M K10 contain illite, quartz, and feldspars as additional components; M SWy-2 contains $8 \%$ quartz and $16 \%$ feldspars as minor components. Montmorillonite can account for ice nucleation up to $240 \mathrm{~K}$ (freezing onset of standard sites) with peak maxima at 236-237 K. M SWy-2 shows a strong special peak for higher suspension concentrations, which might arise from the feldspar component. The kaolinite samples $\mathrm{KGa}-2$ and $\mathrm{KGa}-1 \mathrm{~b}$ from CMS proved to be almost mineralogical pure kaolinite, while kaolinite from Sigma Aldrich (K-SA) consists of only $83 \%$ kaolinite with additional shares of $5 \%$ illite and $5 \%$ K-feldspar (Atkinson et al., 2013). KGa$1 \mathrm{~b}$ and KGa-2 nucleate ice up to $242 \mathrm{~K}$ with $f_{\text {act }}=0.041$ and 0.11 , respectively, and show peak maxima at $237-238 \mathrm{~K}$ (this work and Pinti et al., 2012). While the kaolinite fraction gives rise to the average freezing peak in the DSC thermograms of K-SA, the minor fractions of illite and K-feldspar can account for the special freezing peak which appears for higher suspension concentration in the DSC thermogram. Illite references (illite SE and illite NX) exhibit broad peaks with maxima at $239-242 \mathrm{~K}$ and can account for heterogeneous freezing up to $246 \mathrm{~K}$ with an active fraction of 0.18 and 0.12, respectively. Pinti et al. (2012) and Atkinson et al. (2013) report illite as major component of illite NX and illite SE together with minor fractions of feldspar, however, without specifying the exact type of feldspar. The heterogeneous freezing signal in the DSC thermograms of illite SE and illite NX arises most probably from the main illite component of the sample. The minor feldspar component might be responsible for the tail to high temperature of the freezing peak of illite SE.

\section{Discussion}

\subsection{Number size distributions}

The number size distributions of the natural dust samples have mode diameters between 216 and $479 \mathrm{~nm}$ (see Table 1). Except for the commercially available ATD, the only preprocessing applied to the samples was sieving with a grid of $32 \mu \mathrm{m}$. This led to a strong reduction of the sample volume (by a factor of 100-1000), especially for the dune samples from Qatar and Oman. Although the sieved samples retained particles with diameters up to $32 \mu \mathrm{m}$, the remaining fraction is clearly dominated by particles in the submicron range in terms of number. The dune samples from Qatar and Oman might be coarser, but no size distributions could be obtained because not enough material remained after sieving. Milling of the reference minerals resulted in similar size distributions as those observed for the natural samples. The finest powder was obtained for adularia 2 (mode diameter of $249 \mathrm{~nm}$ ), the coarsest one for labradorite $(467 \mathrm{~nm})$. 
Airborne mineral dust particles cover a large size range from less than 0.1 to more than $100 \mu \mathrm{m}$ (Maring et al., 2003). In dust plumes, also particles with diameters up to $30-40 \mu \mathrm{m}$ are transported over long distances (Wagner et al., 2009; Reid et al., 2013; Kandler et al., 2011a, b). Ground-based and airborne measurements of aerosols show that mineral dust number size distributions are dominated by submicron particles for turbid to clear conditions and particles $<2 \mu \mathrm{m}$ in diameter in dust plumes (Kandler et al., 2009, 2011a, b). Niedermeier et al. (2014) derived a lognormal number size distribution for mineral dust transported to the Cape Verde that peaks at $800 \mathrm{~nm}$. Boose et al. (2016) determined number concentrations of natural mineral dust samples that peak in number concentrations between 200 and $400 \mathrm{~nm}$ diameters with no systematic difference between airborne and ground-collected ones. We therefore conclude that the natural dust samples obtained in this study by sieving with a $32 \mu \mathrm{m}$ grid reflect the number size distributions of airborne mineral dusts reasonably well in view of the overall variability given by source regions, emission, and transport processes.

\subsection{Correlation between mineralogical composition and freezing behaviour of the natural dust samples}

\subsubsection{Emulsion experiments}

In the following, we compare the freezing characteristics of the reference samples with the ones of the dust samples to investigate whether the freezing behaviour of the natural dusts can be explained in terms of their mineralogy. For this qualitative analysis, we use the active particle fractions $f_{\text {act }}$ listed in Tables 2 and 5 and the freezing characteristics observed in the DSC thermograms.

\section{Reference minerals}

Quartz shows ice nucleation activity up to $247 \mathrm{~K}$, however, with a low active particle fraction, $f_{\text {act }}$, of only about 0.01 . Montmorillonites can account for freezing up to $240 \mathrm{~K}$ with $f_{\text {act }}$ of around 0.09 , if one takes M STX-1b as most representative, kaolinite for freezing up to $242 \mathrm{~K}$ with $f_{\text {act }}=0.04$ 0.11 , and illite for freezing up to $246 \mathrm{~K}$ with $f_{\text {act }}=0.12-$ 0.18 . We take plagioclase as representative of $(\mathrm{Na}, \mathrm{Ca})$ feldspars, which can account for immersion freezing up to $240 \mathrm{~K}$ but only with $f_{\text {act }}=0.006$. The microcline reference minerals from Elba $(\mathrm{E})$ and Namibia $(\mathrm{N})$ have a freezing peak with a maximum at $250-251 \mathrm{~K}$ and active particle fractions of 0.64 and 0.54 , respectively. Sanidine can account for freezing up to $242 \mathrm{~K}$ with $f_{\text {act }}=0.03$ and shows a peak maximum at 238-239 K. Adularia can account for freezing up to $246 \mathrm{~K}$ with $f_{\text {act }}=0.008$ and shows a peak maximum at 239$240 \mathrm{~K}$. Since no orthoclase was identified for the orthoclase minerals, and hardly any ankerite in the ankerite sample, we cannot use them as references. We consider the ice nucleation activity of dolomite, dolostone, ankerite, muscovite, and cal- cite as too low to contribute significantly to immersion freezing of the natural dusts. Finally, some of the identified minerals in the natural dusts are water soluble and led to a freezing point depression when they dissolved in the suspensions. These minerals are halite $(\mathrm{NaCl})$, thenardite $\left(\mathrm{Na}_{2} \mathrm{SO}_{4}\right)$, and trona $\left(\mathrm{Na}_{3}\left(\mathrm{CO}_{3}\right)\left(\mathrm{HCO}_{3}\right) \times 2 \mathrm{H}_{2} \mathrm{O}\right)$.

Inspection of the natural dust samples with respect to these reference minerals reveals the following dependencies:

1. The Antarctica sample has an active particle fraction $f_{\text {act }}=0.067$ and two distinct freezing peaks in the DSC thermograms with maxima at 241-243 and 251-252 K, which are present already at the lowest suspension concentrations. The plagioclase component $(21.7 \%)$ can account for the freezing peak at lower temperature, the microcline component $(12.8 \%)$ for the one at higher temperature.

2. Arizona test dust is abundant in mineralogical components that are ice nucleation active and the $5 \mathrm{wt} \%$ suspension has indeed a high active particle fraction $f_{\text {act }}=0.51$. At lower suspension concentrations, illite, kaolinite, sanidine, microcline, and smectite contribute to the DSC signal; at high suspension concentrations the maximum of the freezing peak shifts to $250-251 \mathrm{~K}$ and can be attributed to the microcline component.

3. The Bolivia sample has an active particle fraction $f_{\text {act }}=0.025$. Its DSC thermogram can be explained by the presence of smectite (montmorillonite), kaolinite, and plagioclase at lower freezing temperatures and for lower concentrations. No mineralogical component could be identified which would account for the peaks at higher temperature which appear at higher suspension concentrations.

4. The Etosha sample has an active particle fraction $f_{\text {act }}=0.32$ and a broad heterogeneous freezing peak with onset at $247 \mathrm{~K}$ and two maxima at about 242.5 and $239.5 \mathrm{~K}$. None of the identified minerals can explain this high ice nucleation efficiency. The Etosha sample has a high share of ankerite $(22.8 \%)$, but as the reference stones turned out to be calcite, we lack an ankerite reference for comparison with the dust sample. Ankerite is mineralogically similar to calcite. Since calcite is hardly ice nucleation active, the same might be true for ankerite.

5. The Hoggar Mountain dust sample has $f_{\text {act }}=0.063$ in immersion freezing mode, which can be explained by the presence of sanidine, kaolinite, smectite (montmorillonite), and illite for freezing at lower temperatures and lower suspension concentrations. Illite seems to dominate heterogeneous freezing at higher temperatures and concentrations. Pinti et al. (2012) already pointed out the similarity between the freezing signal of Hoggar Mountain dust and illite with slightly higher 
onset freezing temperatures for Hoggar Mountain dust than for illite.

6. The Israel samples show $f_{\text {act }}=0.12-0.14$, despite their high shares of calcite $(65-68 \%)$. The heterogeneous freezing signal seems to be a superposition of ice nucleation induced by the many minor components present in the samples. The peak at $244 \mathrm{~K}$ appearing at higher suspension concentration can be ascribed to illite. However, the amount of illite measured in the Israel samples seems too low to fully explain this peak.

7. The Makgadikgadi samples contain water-soluble components such as halite, trona, and thenardite, which dissolve in the aqueous suspensions and lead to a freezing point depression. This explains the shift of the homogeneous freezing peak to lower temperatures with increasing suspension concentration. Makgadikgadi A contains several components that can account partly for the quite high active particle fraction $f_{\text {act }}=0.23$ (quartz, plagioclase, smectite). With increasing suspension concentrations, additional peaks at higher temperature appear in the DSC thermograms. This seems to indicate that the DSC signal can be attributed to ice nucleation by major components at lower suspension concentrations and by minor components at higher concentration. Although most identified components of Makgadikgadi A are ice nucleation active, they cannot fully explain the observed peaks at higher suspension concentrations in the thermograms. The sample contains $3 \%$ adularia, which can only partly explain the signal peaking at $245 \mathrm{~K}$. Similarly, ice nucleation by the reference minerals that were identified for Makgadikgadi B cannot fully explain freezing above $242 \mathrm{~K}$ observed at higher suspension concentrations for this sample. Makgadikgadi $\mathrm{C}$ has a quite low active fraction $f_{\text {act }}=0.037$, in agreement with its quite high share of calcite (43\%), which does not contribute to heterogeneous freezing. The presence of kaolinite $(10 \%)$ and smectite $(20 \%)$ can explain the DSC signal peaking at $237 \mathrm{~K}$. The shoulder at $242 \mathrm{~K}$ observed for the highest suspension concentration can only be partly explained by the adularia component $(3 \%)$.

8. The dune dusts from Oman and Qatar contain the main mineralogical components quartz, calcite, and dolomite, which show hardly any ice nucleation activity. This is consistent with the weak heterogeneous signal observed for these samples. The higher ice nucleation activity observed for the Qatar sample can be explained by the presence of microcline.

In summary, the mineralogical composition can qualitatively explain the observed freezing behaviour of 5 of the investigated 12 natural dust samples (Antarctica, ATD, Hoggar Mountain, Oman, and Qatar dusts), and partly for 6 samples
(Bolivia, Israel 1 and 2, Makgadikgadi A, B, and C dusts). There were no mineral components identified for the Etosha sample that would explain its high freezing efficiency. This shows that the mineralogical composition is a major determinant of the ice nucleation ability of natural mineral dust samples, but cannot explain it to the full extent. Assuming that the mineralogical composition was identified correctly, additional factors such as mixing state, morphology, and surface defects might also influence the nucleation ability (see Sect. 6.4 for further discussion).

\subsubsection{Bulk experiments}

Natural dust samples show bulk freezing temperatures in a compact range from 255 to $265 \mathrm{~K}$, while reference minerals span a broad range from 250 to $272 \mathrm{~K}$ (Fig. 4). Comparison with freezing temperatures observed for emulsion samples shows that experiments with suspensions containing a high number of particles do not represent the freezing behaviour of typical INPs in a sample. Since one nucleation event initiates the freezing of the whole sample, impurities well below the detection limit of the XRD measurements might cause freezing. Nevertheless, there is a weak correlation between bulk and emulsion freezing temperatures. Figure 6 depicts this correlation for the $10 \%$ heterogeneously frozen fraction $\left(T_{\text {het }, 10 \%}\right)$ in the emulsion experiments performed with 0.5 and $10 \mathrm{wt} \%$ suspensions. Samples with high freezing temperatures in emulsion experiments exhibit in general also high bulk freezing temperatures. This is the case for the natural samples (Fig. 6a) as well as for the reference minerals (Fig. 6b). An outlier is montmorillonite K-10 with high bulk freezing but low emulsion freezing temperatures. The presence of a correlation suggests that the best sites which are responsible for freezing of bulk samples are not random impurities but related to the mineralogical composition. Samples containing microcline (Antarctica, ATD, microclines E and $\mathrm{N}$, and orthoclase 2) are among the ones with the highest bulk freezing and emulsion freezing temperatures. Calcite, dolomite, and dolostone with low ice nucleation activity in emulsion experiments also show low bulk freezing temperatures.

\subsection{Active particle fraction $f_{\text {act }}$}

Depending on size and suspension concentration, droplets of the investigated emulsions may be empty or contain one or a few particles. Empty droplets as well as droplets containing only ice nucleation inactive particles contribute to the homogeneous freezing signal in the DSC curves. Tables 2 and 5 list the average diameter of a droplet with 1 particle inside for $2 \mathrm{wt} \%$ suspensions in the second column $D_{\mathrm{p} 1}$, indicating that smaller particles are empty and larger ones contain one or a few particles. Assuming that all particles are able to nucleate ice, the heterogeneously frozen water volume fraction, $p_{\text {het }}$, can be calculated and compared with the 

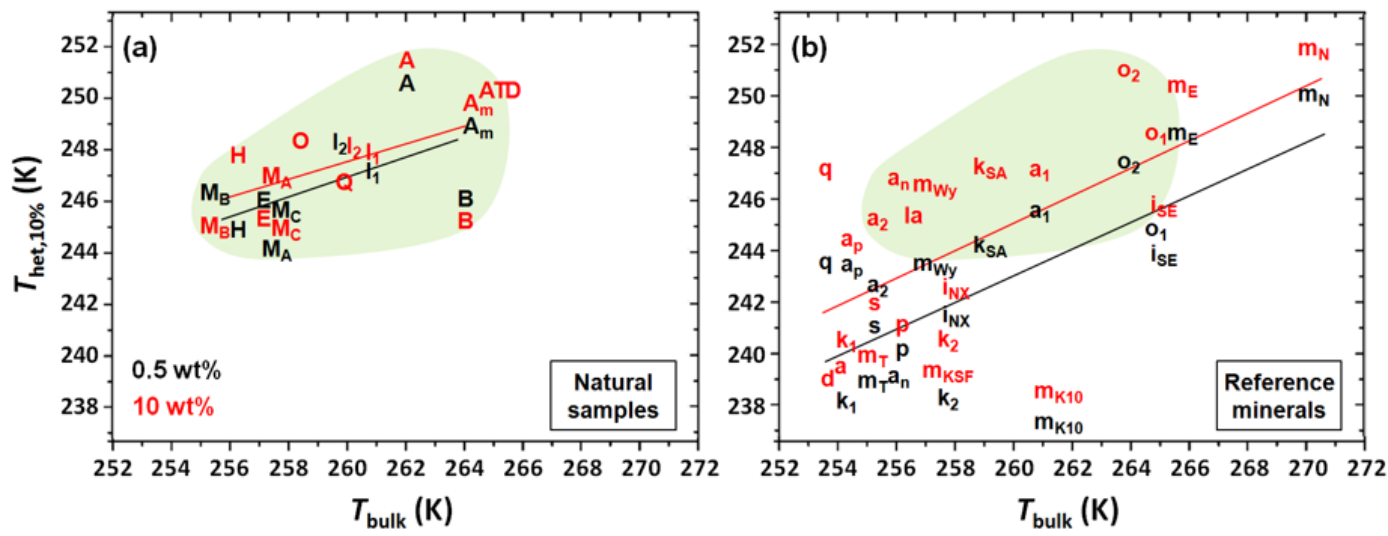

Figure 6. Correlation between bulk and emulsion freezing of the natural dust samples (panel a) and reference samples (panel b). Average bulk freezing temperatures are plotted against temperatures of $10 \%$ heterogeneously frozen fraction $\left(T_{\text {het, } 10 \%}\right)$ for suspensions with concentrations of $0.5 \mathrm{wt} \%$ (black numbers) and $10 \mathrm{wt} \%$ (red numbers). Slopes are $0.0007 \pm 0.0004$ (0.5 wt \% suspension) and $0.0006 \pm 0.0003$ (10 wt \% suspension) for the natural dust samples (panel a) and $0.0009 \pm 0.0003(0.5$ and $10 \mathrm{wt} \%$ suspensions $)$ for the reference samples (panel b). Sample code for the natural dust samples (panel a): Antarctica (A), Antarctica milled (Am), Arizona test dust (ATD), Bolivia (B), Etosha (E), Hoggar $(\mathrm{H})$, Israel 1 and $2\left(\mathrm{I}_{1}, \mathrm{I}_{2}\right)$, Makgadikgadi $\mathrm{A}, \mathrm{B}$ and $\mathrm{C}\left(\mathrm{M}_{\mathrm{A}}, \mathrm{M}_{\mathrm{B}}, \mathrm{M}_{\mathrm{C}}\right)$, Oman $(\mathrm{O})$, Qatar (Q). Sample code for the reference minerals (panel b): ankerite (a), dolomite (d), quartz (q), adularia 1 and $2\left(a_{1}, a_{2}\right)$, microcline $E$ and $N\left(m_{E}, m_{N}\right)$, orthoclase 1 and $2\left(\mathrm{o}_{1}\right.$ and $\left.\mathrm{o}_{2}\right)$, sanidine $(\mathrm{s})$, albite (pericline) $\left(\mathrm{a}_{\mathrm{p}}\right)$, anorthite $\left(\mathrm{a}_{\mathrm{n}}\right)$, labradorite (la), plagioclase (p), illite NX and SE (iNX, isE), kaolinite KGa-1b, KGa-2 and SA ( $\left.\mathrm{k}_{1}, \mathrm{k}_{2}, \mathrm{k}_{\mathrm{SA}}\right)$, montmorillonite K-10, KSF, STx-1b, and SWy-2 ( $\mathrm{m}_{\mathrm{K} 10}, \mathrm{~m}_{\mathrm{KSF}}, \mathrm{m}_{\mathrm{T}}$, my $)$. Green shading: typical freezing temperatures of natural samples.

measured one, $p_{\text {het,lab }}$. The ice nucleation active particle fractions were calculated for all concentrations and are given in Tables 2 and 5 for the $2 \mathrm{wt} \%$ suspensions. They range $f_{\text {act }}=0.025-0.32$ (Table 2) for the natural dust samples excluding ATD and $f_{\text {act }}=0.0004-0.64$ for the reference minerals (Table 5). Ideally, the derived active particle fractions should be independent of suspension concentration. If particles aggregated in suspension, the active particle fraction would be underestimated because the effective number of empty droplets would be larger than the one determined from the size distribution of the dry aerosol. Stronger aggregation is expected at higher concentration leading to an increasing low bias with increasing suspension concentration. To elucidate whether such a tendency is present, the ratios of $f_{\text {act }}$ of 0.5 and $2 \mathrm{wt} \%$ suspensions, $f_{\text {act }}(0.5) / f_{\text {act }}(2)$, and the ratio of $f_{\text {act }}$ of 2 and $10 \mathrm{wt} \%$ suspensions, $f_{\text {act }}(2) / f_{\text {act }}(10)$, are also listed in Tables 2 and 5. For most natural dust samples the ratios are $>1$, indicating some aggregation. The reference samples give a less clear picture. The ratios show quite a large scatter with values between 0.5 and 2 and a tendency to values $>1$, indicating aggregation in some cases. Pinti et al. (2012) have discussed the possibility of aggregation for clay minerals concluding that kaolinites show quite strong aggregation mainly at low $\mathrm{pH}$; no aggregation is expected for montmorillonites while no clear information could be obtained for illites. Emersic et al. (2015) hypothesized a possible influence of coagulation to explain the discrepancy between wet-suspension- and dry-dispersion-derived ice nucleation efficiency of mineral particles using kaolinite, illite NX, and a K-feldspar as examples. They showed aggregation for kaolinite using dynamic light scattering but did not present corresponding data for illite and the K-feldspar.

The minerals calcite, dolomite, and dolostone are virtually ice nucleation inactive and the heterogeneous freezing observed for these samples could also be due to impurities instead of the minerals themselves. Microclines proved to be exceptionally good ice-nucleating minerals with $f_{\text {act }}=0.54$ for microcline $\mathrm{E}$ and $f_{\text {act }}=0.64$ for microcline N. Considering the large uncertainties associated with $f_{\text {act }}$ (see Appendix A) even all particles might be ice nucleation active. This is supported by the DSC thermograms featuring the complete decline of the heterogeneous signal before homogeneous freezing sets in. Most other reference minerals have $f_{\text {act }}=0.01-0.1$ indicating the presence of particles that do not act as INPs. Accounting for a potential low bias because large particles may be missed when size distributions are determined by SMPS/APS (see Appendix A), $f_{\text {act }}$ could rise to $0.05-0.5$ but should remain clearly below unity. A value of $f_{\text {act }}$ significantly below 1 is further supported by the observation that heterogeneous nucleation is still ongoing when homogeneous freezing sets in.

Assuming ice nucleation to occur on active sites, whose occurrence can be described by a probability density as a function of surface area (e.g. Marcolli et al., 2007; Lüönd et al., 2010), the inactive particles are more likely the smallest ones. Our data cannot confirm or reject this relation because in our experiments the whole distribution of particles is investigated without any extra information on size dependence. There is also hardly any direct proof for such a relationship from other studies on immersion freezing. The mineral dusts 
chosen to study size-selected particles of different diameters were mostly mixtures of minerals, so that different particle sizes could correlate with different mineralogical composition.

Such a case is ATD, as it is a complex mixture of minerals (see Table 3). With the Leipzig Aerosol Cloud Interaction Simulator (LACIS), Niedermeier et al. $(2010,2011)$ investigated ice nucleation in immersion mode for $300 \mathrm{~nm}$ ATD particles and determined ice active fractions of $f_{\text {act }}=0.04$ at $239 \mathrm{~K}$. This fraction increased to 0.3 at $235 \mathrm{~K}$ and reached 1.0 only at $234 \mathrm{~K}$ due to homogeneous ice nucleation. In a continuous flow diffusion chamber (CFDC), Hoyle et al. (2011) measured maximum activated fractions of 0.8 for $800 \mathrm{~nm}$ diameter ATD particles before homogeneous ice nucleation set in. This result was confirmed by Nagare et al. (2016), who measured $f_{\text {act }} \leq 1$ before homogeneous freezing set in for $800 \mathrm{~nm}$ ATD particles with the same CFDC. The active site parameterization developed by Marcolli et al. (2007) based on DSC experiments agrees well with these experiments. It further predicts that, on average, ATD particles need to be larger than $200 \mathrm{~nm}$ to bear an active site inducing heterogeneous freezing before homogeneous ice nucleation sets in. A $300 \mathrm{~nm}$ diameter ATD particle should contain, on average, an active site that induces heterogeneous freezing within $10 \mathrm{~s}$ at $237 \mathrm{~K}$. In this study, the ATD sample was used without any size selection, yielding $f_{\text {act }}=0.51$. A value of $f_{\text {act }}$ significantly below 1 is confirmed by the fact that the heterogeneous signal is still present when homogeneous ice nucleation sets in. The size distribution determined for ATD peaks at $354 \mathrm{~nm}$. The fraction of particles with diameters below $300 \mathrm{~nm}$ is 0.393 , the fraction below $200 \mathrm{~nm}$ is 0.174 . This explains $f_{\text {act }}<1$ in our experiments.

Kaolinite KGa-1b from CMS has been investigated by several groups. Re-evaluating the data presented in Pinti et al. (2012), yields $f_{\text {act }}=0.041$. If we account for a low bias, this number might rise at maximum to $f_{\text {act }}=0.2$. A value of $f_{\text {act }}$ well below 1 is in accordance with the DSC thermogram (Pinti et al., 2012) with an overlap of the homogeneous and heterogeneous ice freezing peaks, showing that heterogeneous nucleation is still ongoing when homogeneous ice nucleation sets in. Wex et al. (2014) investigated $300 \mathrm{~nm} \mathrm{KGa-}$ $1 \mathrm{~b}$ particles and determined a nucleation rate coefficient. If their parameterization is applied to $300 \mathrm{~nm}$ particles and a residence time of $10 \mathrm{~s}, f_{\text {act }}=1$ is expected at $236 \mathrm{~K}$ when homogeneous nucleation sets in. Active fractions of 0.5 and 0.1 are expected for 200 and $100 \mathrm{~nm}$ particles, respectively. The size distribution of KGa- $1 \mathrm{~b}$ peaks at $302 \mathrm{~nm}$. The share of particles $<200$ and $<100 \mathrm{~nm}$ is 0.241 and 0.0294 , respectively. Therefore, the active particle fraction of KGa- $1 \mathrm{~b}$ observed in our experiments seems rather low when compared with the parameterization of Wex et al. (2014). An explanation for this might be aggregation of kaolinite in suspension.

In experiments with a CFDC, Lüönd et al. (2010) measured active particle fractions of almost one for droplets containing one kaolinite (K-SA) particle with diameter of 200 and $400 \mathrm{~nm}$, and one when droplets contained an $800 \mathrm{~nm}$ particle. These numbers are higher than $f_{\text {act }}=0.13$ that we determined for K-SA in our experiments. Wex et al. (2014) observed frozen fractions up to 0.5 for $700 \mathrm{~nm}$ K-SA particles. Hartmann et al. (2016) determined frozen fractions at $236 \mathrm{~K}$ of 0.1 for $300 \mathrm{~nm}$ and of 0.3 for $700 \mathrm{~nm} \mathrm{K-SA}$ particles and they found an exponential increase of the freezing probability with the increase of surface area of K-SA present in the droplet by comparing 300,700, and $1000 \mathrm{~nm}$ particles. These results are in accordance with our ice nucleation active fraction of 0.13 determined for K-SA when taking measurement uncertainties and the influence of the time available for nucleation into account (Welti et al., 2012).

In summary, it is very likely that mineral particles are present in samples of mineral dusts that are ice nucleation inactive. For mineralogically pure samples, the inactive particle fraction seems to correlate with particle size. For natural dusts, which are mixtures of minerals, this fraction probably correlates with the mineralogical composition because the analysis of the reference samples has shown a great variability of ice nucleation activity depending on mineralogy. However, there are also discrepancies in the active particle fractions, when these are determined with different instruments. These discrepancies must be due to systematic errors, which are currently not well understood and are not taken into account in any error estimates.

\subsection{Importance of mineralogy vs morphology and surface structure for ice nucleation ability}

In this study, we compare freezing characteristics of natural dust samples with those of reference samples. The reference samples were powders obtained from milling of mineral stones. To investigate the influence of milling, we compare the $<32 \mu \mathrm{m}$ fraction of the Antarctica sample, once in its original state and once milled (see Sect. 4.1, Table 2, and Fig. 3a). No significant change in terms of active particle fraction $f_{\text {act }}$ can be observed, when comparing the results for the sieved Antarctica sample with the results for the sieved and milled Antarctica sample. The 10, 25, and $50 \%$ heterogeneously frozen volume is slightly higher for the milled Antarctica sample. An explanation for this could be that the microcline concentration in terms of number of particles might increase due to milling since feldspar particles (amongst them microcline) are typically larger than, e.g. clay mineral particles (e.g. Boose et al., 2016). The milling of the sample reduced the mode diameter $d_{\mathrm{m}}$ of the lognormal distribution from $383 \pm 3$ to $288 \pm 0.8 \mathrm{~nm}$. Comparison of the thermograms shown in Fig. 3a shows that milling indeed influences the freezing behaviour of the sample. Milling of the sample leads to a shift of the main peak to higher temperature and the disappearance of the high temperature peak at about $253 \mathrm{~K}$. A part of these changes might be attributed to the increased occupation of droplets by particles since the number of particles per mass increased (see Table 2). How- 
ever, the disappearance of the high temperature peak points to additional surface modifications. This shows that physical treatment like milling influences the freezing behaviour of samples in a complex way. Hiranuma et al. (2015) found a higher freezing efficiency for milled hematite particles. Similarly, Zolles et al. (2015) found an increase of freezing temperature by milling for quartz samples and a marginal increase for feldspar samples. Boose et al. (2016) showed that milling can have a major effect on the ice nucleation activity of multicomponent samples when the mineralogical composition is particle size dependent and the experiments are carried out on size-selected samples. If the coarse fraction of a sample consists of minerals with a low ice nucleation activity, the ice nucleation activity of the sample will be reduced after milling, when only the fine particle fraction is investigated for ice nucleation. The opposite can be the case when the particles in the coarse fraction show a high ice nucleation activity.

For some natural dust samples (Bolivia, Makgadikgadi A and B) freezing peaks observed at higher temperatures for higher suspension concentrations cannot be explained by mineralogical composition. This raises the question about the importance of morphology and the surface structure. These two aspects cannot be investigated by XRD measurements. Single particle analysis by scanning electron microscopy (SEM) and X-ray fluorescence (XRF) of airborne and surface collected dust particles during PRIDE showed that $50 \%$ of all particles were present in some form of aggregates of different minerals (Reid et al., 2003). The larger clay minerals were usually found to be carrying smaller particles of, e.g. iron oxide (Reid et al., 2013). Kandler et al. (2011a) found that aggregates were least frequent for particles in the submicron size range, since they are in the same size range as the primary grains. The aggregate structure became more complex for particles between 1 and $2.5 \mu \mathrm{m}$ and most particles between 2.5 and $10 \mu \mathrm{m}$ had aggregated structures. If the contact lines between aggregates performed as preferential sites for ice nucleation, this might explain the higher nucleation ability of some natural dust samples compared with the reference samples they are composed of. In addition, active sites such as steps, cracks and cavities (Kulkarni and Dobbie, 2010; Hiranuma et al., 2014; Zolles et al., 2015) might be more frequent in naturally aged samples collected in deserts than in milled stones. Moreover, the presence of biological material has been discussed to increase the ice nucleation ability of dusts (DeMott et al., 2003; Baker et al., 2005; Pratt et al., 2009; Conen et al., 2011; Hallar et al., 2011; Creamean et al., 2013). Peckhaus et al. (2016) investigated four milled feldspar minerals in freezing experiments. Bulk mineralogical composition determined by XRD revealed the three K-rich samples to consist mainly of microcline $(76-80 \%)$ with a minor ( $\mathrm{Na}, \mathrm{Ca})$-feldspar component (16-24\%). They used an environmental scanning electron microscope to record images of single particles and energy dispersive X-ray (EDX) to infer the mineralogical compo- sition of the particles. The SEM images showed agglomerates consisting of several large particles with smaller particle fragments on their surface. The (Na, Ca)-feldspar sample exhibited large interparticle variability in $\mathrm{Na}: \mathrm{Ca}$ ratio. The Krich feldspar particles contained varying amounts of sodium and also calcium. Only one K-rich feldspar contained some pure K-feldspar particles with no share of sodium. Interestingly, this sample showed the highest freezing temperatures.

\section{Atmospheric implications and implementation into models}

We consider the natural dust samples investigated here to be representative of atmospheric mineral dust. Most of them were collected from the ground in dust source regions that contribute frequently to the airborne long-range transport. The sieving of the samples with a $32 \mu \mathrm{m}$ grid rendered them comparable in size with atmospheric mineral dusts, but left the particles otherwise unchanged.

A surprising finding is that the distribution of freezing temperatures of the investigated natural dusts is much more compact than that of the reference minerals for both emulsion measurements (characterizing the typical INP) and bulk measurements (characterizing the best INP). The freezing temperatures $T_{\text {het, } 10 \%}$ of natural dusts with $5 \mathrm{wt} \%$ suspension concentration span about $6 \mathrm{~K}$, but those of reference minerals about $12 \mathrm{~K}$ (see Fig. 4). Therefore, the reference samples extend far beyond the range covered by the natural dusts in terms of high (as well as low) ice nucleation efficiencies. The dust mixing and/or dust aging (e.g. by coatings) in the natural environment appears to prevent extreme ice nucleation efficiencies (high or low). However, mineralogical composition does matter. Quartz particles were present in all samples (cp. Table 3) of the nine investigated regions (locations 1-9 in Fig. 2). Further, calcite, (Na, Ca)-feldspars (plagioclase), and clay minerals (mainly smectite) were present in seven of the nine regions. K-feldspars (adularia, microcline, orthoclase, and sanidine) were identified still in six regions, however, only the Antarctica, ATD, and Qatar dune samples contained microcline, and the latter only as a minor fraction. These compositions compare very well with the ones of atmospheric mineral dusts compiled by Murray et al. (2012), confirming their assertion that mineral dusts cannot fully account for the high freezing temperatures (above $261 \mathrm{~K}$ ) observed in the atmosphere. A notable exception might be microcline-containing samples, for which the mineral reference sample microcline N (see Fig. 4) shows bulk freezing even above $270 \mathrm{~K}$. However, out of the 10 investigated samples from dust source regions, microcline was only detected in the Qatar dune sample, and then only as a minor component (4\%). Curiously, this sample did not exhibit a particularly high ice nucleation efficiency (Fig. 3). Boose et al. (2016) found microcline present in one out of four investigated airborne dust samples originating from the Sahara and 
in three out of eight surface-collected dust samples. If microcline particles are indeed common in atmospheric dusts, they could be relevant for cloud glaciation at temperatures above $260 \mathrm{~K}$, although from the present study this does not seem to be a very likely scenario. In order to investigate this better, atmospheric aerosol samples would need to be analysed with respect to microcline using XRD.

Evaluation of the active particle fraction $f_{\text {act }}$ showed that only a part of the mineral dust particles is ice nucleation active. The inactive fraction most probably consists of particles which are composed of inactive minerals such as calcite or muscovite. These particles might at the same time belong to the fraction of particles with smaller size, because larger particles are usually aggregates of different minerals (Reid et al., 2003; Kandler et al., 2011a) and thus more likely contain a mineral that is ice nucleation active. A size dependency is also in accordance with DeMott et al. (2010), who found that the concentrations of INPs active at mixed-phase cloud conditions can be related to the number concentrations of particles larger than $0.5 \mu \mathrm{m}$ in diameter. Size-selective ice nucleation experiments with pure mineral samples, such as kaolinite, show that larger particles are indeed more effective INPs than smaller ones. This justifies a parameterization of immersion freezing based on particle surface area, as developed by Niemand et al. (2012). The good correlation between mineralogical composition and freezing behaviour suggests that more sophisticated parameterizations should rely on the mineralogical composition based on a source scheme of dust emissions as done by Hoose et al. (2008).

\section{Summary and conclusions}

Natural dusts and milled reference minerals were analysed with the objective to investigate whether their ice nucleation activity shows significant differences between different source regions and whether the freezing behaviour can be related to the mineralogical composition. The natural dust samples consisted of calcite, quartz, clay minerals, K-feldspars, and ( $\mathrm{Na}, \mathrm{Ca}$ )-feldspars as major mineralogical components, which is in good agreement with the mineralogical composition of atmospheric mineral dusts. With number distributions that peak for diameters $<1 \mu \mathrm{m}$, they are also comparable in size.

The ice nucleation ability of the reference minerals show large variations, much larger than found for the natural dusts investigated in this work. Calcite, dolomite, dolostone, and muscovite seem to induce hardly any freezing. For these minerals, ice nucleation, if present, might not be related to the mineral composition but controlled by impurities. Microcline is able to induce freezing at higher temperatures than all other investigated minerals. In addition, more or less all particles in the two investigated microcline samples are active as INPs. This makes this K-feldspar an exceptionally good ice-nucleating mineral and superior to all other analysed Kfeldspars, (Na, Ca)-feldspars, and the clay minerals.

The XRD analysis of the natural dust samples showed that quartz particles were present in dusts from all source regions. (Na, Ca)-feldspars (plagioclase) and clay minerals (mainly smectite) were present in dusts from most source regions. Kfeldspars were identified in several source regions; however, only the Qatar dune sample contained microcline as a minor fraction - besides ATD and Antarctica samples, which are not considered to be from typical source regions.

The natural dust samples show very similar freezing temperatures except Antarctica and ATD. These two samples were not collected in source regions of mineral dust aerosols but included as examples of very remote regions or of commonly used reference dust. For all natural dust samples without Antarctica and ATD, $10 \%$ heterogeneously frozen fraction is realized between 244 and $250 \mathrm{~K}$. The $25 \%$ heterogeneously frozen fraction is between 242 and $246 \mathrm{~K}$, and the $50 \%$ heterogeneously frozen fraction is between 239 and $244 \mathrm{~K}$. Bulk freezing occurred between 255 and $265 \mathrm{~K}$. The natural dust samples show active particle fractions $f_{\text {act }}=$ $0.025-0.32$. Taking a potential low bias in our evaluation into account, these numbers might rise to $f_{\text {act }}=0.1-1$. Active particle fractions significantly below 1 are expected considering the share of very small particles and inactive mineral components present in the dusts.

Qualitatively, the mineralogical composition can fully explain the observed freezing behaviour of 5 of the investigated 12 natural dust samples, and partly for 6 samples. Only for the Etosha sample no mineral components could be identified that would explain its high freezing efficiency. This shows that in general the mineralogical composition is a major determinant of the ice nucleation ability of natural mineral dust samples, but cannot entirely explain it. Agglomeration of particles and surface erosion could lead to additional changes in active sites of natural dusts, either enhancing or reducing their efficiency, in comparison to freshly milled reference samples. Comparison of the DSC thermograms of only sieved and additionally milled Antarctica dust shows that milling indeed influences the freezing behaviour and possibly the surface structure of the sample.

The findings of this study are in agreement with previous work that the mineral dusts can hardly account for the glaciation of clouds observed at the highest temperatures in the atmosphere. A notable exception is microcline, for which the temperature of $50 \%$ heterogeneously frozen fraction occurs above $245 \mathrm{~K}$ for all concentrations. For the microcline from Namibia, bulk freezing temperatures were even above $270 \mathrm{~K}$. If microcline turns out to be common in atmospheric mineral dusts, this conclusion could be revised. To resolve this question, analysis of airborne dust samples with XRD is necessary, on bulk samples or by EDX on single particles.

While this study shows that mineralogical composition is a major determinant of ice-nucleating ability, in practice most natural samples consist of a mixture of minerals, and 
this mixture seems to lead to remarkably similar ice nucleation abilities, regardless of their exact composition, so that global models, in a first approximation, may represent mineral dust as a single species with respect to ice nucleation activity. This finding confirms the conclusions by DeMott et al. (2015), who suggested that as a useful first-order approximation in numerical modelling, all mineral dust can be considered as a single type of ice-nucleating particles. However, more sophisticated representations of ice nucleation by mineral dusts should rely on the mineralogical composition based on a source scheme of dust emissions.

\section{Data availability}

To get access to the DSC data and number size distributions, please contact Claudia Marcolli (claudia.marcolli@env.ethz.ch). 


\section{Appendix A: Uncertainties of the fraction of active INPs}

Different kinds of uncertainties concerning the calculation of the active particle fraction $f_{\text {act }}$ are presented in this section.

\section{A1 Uncertainty in calculation of size distribution}

The uncertainty stemming from the size distribution of the dust particles is the largest one. The particles were aerosolized in a fluidized bed aerosol generator for APS and SMPS measurements. Due to the fact that particles $>1 \mu \mathrm{m}$ tend to sediment quite fast, larger particles might not be measured appropriately with the APS. Even if the number of particles with diameter $>1 \mu \mathrm{m}$ is small compared with the total number of particles, the contribution to the mass can be significant and therefore the estimated number of particles for a given mass can change drastically. To estimate this error, two different measurement techniques were used to determine the size distribution of the Hoggar Mountain dust sample, namely SMPS/APS and the evaluation of electron microscope (EM) images (Pinti et al., 2012). The SMPS/APS measurements gave a factor 4.4 higher particle numbers per mass than the EM method. If we assume that all the particles $>16 \mu \mathrm{m}$ diameter sediment too fast to be pipetted into the emulsion, this factor reduces to 2.8 . To be consistent with the evaluation of the other samples, the SMPS/APS measurements were used to calculate $f_{\text {act }}$ in this study. However, we think that the EM evaluation represents better the coarse fraction present in the sample, which would lead to a low bias of $f_{\text {act }}$ listed in Tables 2 and 5. Another uncertainty in the calculation of size distribution is the possibility of aggregation of particles in the suspension, which is discussed in the main part of the paper in Sect. 6.3.

\section{A2 Uncertainty in the calculation of water droplet size distribution}

The second largest uncertainty concerns the stability of the size distribution of the water droplets in the emulsion, which is strongly influenced by the homogeneity of the mineral oillanolin mixture. The homogeneity decreases with time and can be restored by heating up and mixing the mineral oillanolin mixture again. To estimate this uncertainty, samples with the same dust and the same concentration measured at different times (with some months in between) were compared. Over many months $f_{\text {act }}$ varies at most by a factor of 2 due to the changes in the water droplet size distribution. This agrees with the comparison of the droplet size distributions measured at different times.

Figure 1 shows that no water droplets larger than $10 \mu \mathrm{m}$ were found in the optical images of the emulsions. However, extrapolating the lognormal distribution fitted to the volume size distribution, larger droplets should also be present. This introduces another systematic uncertainty to our evaluation. To quantify this uncertainty we extrapolated the volume size distribution of the droplets using the lognormal distribution. Taking the thus obtained fraction of particles $>10 \mu \mathrm{m}$ into account would reduce the active particle fraction by less than $10 \%$. We also considered the error because droplets with diameters $<0.3 \mu \mathrm{m}$ are below the detection limit of the microscope. We estimated that the contribution of these small water droplets to the whole water volume in the emulsion should be $3 \%$ or less. For measurements with less than $80 \%$ heterogeneously frozen volume this changes the number of active particles $f_{\text {act }}$ by a factor of $<1.2$. For heterogeneously frozen fractions of 90 and $95 \%$, this would increase $f_{\text {act }}$ by a factor of 1.4 and 2, respectively. Therefore, this uncertainty seems to influence mainly the samples with high heterogeneously frozen fractions, namely the two microcline samples, the milled Antarctica sample and the ATD sample.

\section{A3 Uncertainty in the separation of heterogeneous and homogeneous freezing peaks}

The separation between the heterogeneous and homogeneous freezing peaks is, to some extent, arbitrary for DSC thermograms with a large overlap. Therefore, the heterogeneous and homogeneous freezing peaks were separated in different ways to evaluate the heterogeneously frozen fraction. For samples where the heterogeneous signal is still high when homogeneous freezing starts, this gave an uncertainty of $f_{\text {act }}$ by a factor of 1.3 for about $10 \%$ heterogeneously frozen fractions), 1.15 for heterogeneously frozen fractions between 20 and $80 \%, 1.3$ for $90 \%$ heterogeneously frozen fractions, and 1.6 for $95 \%$ heterogeneously frozen fractions. Because all samples with heterogeneously frozen fractions $>85 \%$ have clearly separated heterogeneous and homogeneous freezing peaks, the uncertainty concerning the separation of heterogeneous and homogeneous signal is smaller and therefore $f_{\text {act }}$ has an uncertainty of a factor 1.1-1.25 depending on the heterogeneously frozen fraction.

\section{A4 Total uncertainty of the ice nucleation active fraction}

The uncertainties discussed in Sects. A1-A3 give an upper limit for $f_{\text {act }} 5.8$ times (6.7 times for microcline) larger than the calculated value. Taking the effect of aggregation also into account, it might even be larger. Assuming that all dust particles $>16 \mu \mathrm{m}$ sediment too fast to be pipetted into the emulsions, this would reduce the correction factor to 4.2 (5.1 for microcline). The lower limit for $f_{\text {act }}$ is 2.3 times smaller than the calculated value. The correction factor for the lower limit is smaller than for the upper limit because for the calculation of the active particle fraction the particle size distribution measured with SMPS and APS was used. This method gives more particles for a given mass than measuring and counting the particles from electron micrographs. Therefore, the particle size distribution used for calculations can 
Table B1. Comparison of mineralogy of ATD determined by XRD from Atkinson et al. (2013) and this study. The abbreviations stand for ill/mus: illite/muscovite; ka: kaolinite; qu: quartz; Kf: K-feldspars, NCf: (Na, Ca)-feldspars; cal: calcite; sm: smectite; dol: dolomite.

\begin{tabular}{llllllllll}
\hline Natural dusts & ill/mus & $\mathrm{ka}$ & $\mathrm{qu}$ & $\mathrm{Kf}$ & $\mathrm{NCf}$ & $\mathrm{cal}$ & $\mathrm{sm}$ & dol & Others \\
\hline This study & 3 & $<1$ & 23 & 36 & 12 & 1 & 25 & & ankerite $<1$; tremolite $<1$ \\
Atkinson et al. (2013) & 7.5 & 2 & 17.1 & 20.3 & 12.4 & 4.3 & 10.1 & 1.3 & hematite 0.7 \\
\hline
\end{tabular}

be assumed to give an upper limit of the number of particles present per mass.

This error estimation shows that uncertainties of $f_{\text {act }}$ increase for higher suspension concentrations. We therefore assume that the most reliable active particle fractions are determined for lower suspension concentrations. Since the heterogeneous signal for the lowest concentrations is for many samples too weak to be evaluated reliably, we take the $2 \mathrm{wt} \%$ suspension data as representative for $f_{\text {act }}$ since, for this concentration, data for almost all samples are available.

\section{Appendix B: Uncertainties in XRD analysis of mineralogical composition}

Table B1 compares the XRD evaluations of ATD from Atkinson et al. (2013) with the one performed in this study. The differences illustrate the accuracy that can be expected for the determination of mineralogical composition by such analyses. Both identifications found the same minerals present in ATD but with differences in the relative contributions of up to $15 \%$. Atkinson et al. (2013) found small amounts of hematite and dolomite, which were not found in this study. Small amounts of ankerite and tremolite were identified in this study but not by Atkinson et al. (2013). Ankerite and dolomite have very similar XRD diffractograms; therefore, a distinction between these two minerals is (at least for small amounts) quite difficult. ATD is a material composite. There might be variations in exact composition between batches or even within a batch. This might be a reason for discrepancies in addition to the accuracy of the XRD evaluation. 
Acknowledgements. This work was supported by the Swiss National Foundation, project nos. 200021_138039 and 200021_140663. We thank Paolo D'Odorico, Alain Jacot, Esther Mbiti, Christian Rixen, Sonja Wipf, Jens Köhler, Georg Kaser, and Yvonne Boose for providing the natural dust samples; Michael Plötze, Anette Rötlisberger, and Marion Rothaupt for the possibility to do XRD measurements; André Welti, Baban Nagare, and Monika Kohn for providing the SMPS and the APS and the strong support during size distribution measurements; Peter Brack for providing the reference minerals; Alejandro Beltran and Wilfried Winkler for providing the infrastructure for sieving; and Kurt Barmettler for providing the infrastructure to mill the stones. Moreover, we thank Ulrike Lohmann and Yvonne Boose for the helpful discussion.

Edited by: M. Petters

Reviewed by: two anonymous referees

\section{References}

Ansmann, A., Tesche, M., Althausen, D., Müller, D., Seifert, P., Freudenthaler, V., Heese, B., Wiegner, M., Pisani, G., Knippertz, P., and Dubovik, O.: Influence of Saharan dust on cloud glaciation in southern Morocco during the Saharan Mineral Dust Experiment, J. Geophys. Res., 113, D04210, doi:10.1029/2007JD008785, 2008.

Ansmann, A., Tesche, M., Seifert, P., Althausen, D., Engelmann, R., Fruntke, J., Wandinger, U., Mattis, I., and Müller, D.: Evolution of the ice phase in tropical altocumulus: SAMUM lidar observations over Cape Verde, J. Geophys. Res., 114, D17208, doi:10.1029/2008JD011659, 2009.

Atkinson, J. D., Murray, B. J., Woodhouse, M. T., Whale, T. F., Baustian, K. J., Carslaw, K. S., Dobbie, S., O'Sullivan, D., and Malkin, T. L.: The importance of feldspar for ice nucleation by mineral dust in mixed-phase clouds, Nature, 498, 355-358, doi:10.1038/nature12278, 2013.

Augustin-Bauditz, S., Wex, H., Kanter, S., Ebert, M., Niedermeier, D., Stolz, F., Prager, A., and Stratmann, F.: The immersion mode ice nucleation behavior of mineral dusts: A comparison of different pure and surface modified dusts, Geophys. Res. Lett., 41, 7375-7382, doi:10.1002/2014GL061317, 2014.

Augustin-Bauditz, S., Wex, H., Denjean, C., Hartmann, S., Schneider, J., Schmidt, S., Ebert, M., and Stratmann, F.: Laboratorygenerated mixtures of mineral dust particles with biological substances: characterization of the particle mixing state and immersion freezing behavior, Atmos. Chem. Phys., 16, 5531-5543, doi:10.5194/acp-16-5531-2016, 2016.

Baker, J. B., Southard, R. J., and Mitchell, J. P.: Agricultural dust production in standard and conservation tillage systems in the San Joaquin Valley, J. Environ. Qual., 34, 1260-1269, doi:10.2134/jeq2003.0348, 2005.

Beddows, D. C. S., Dall'osto, M., and Harrison, R. M.: An enhanced procedure for the merging of atmospheric particle size distribution data measured using electrical mobility and time-of-flight analysers, Aerosol Sci. Tech., 44, 930-938, doi:10.1080/02786826.2010.502159, 2010.

Boose, Y., Welti, A., Atkinson, J., Ramelli, F., Danielczok, A., Bingemer, H. G., Plötze, M., Sierau, B., Kanji, Z. A., and
Lohmann, U.: Heterogeneous ice nucleation on dust particles sourced from 9 deserts worldwide - Part 1: Immersion freezing, Atmos. Chem. Phys. Discuss., doi:10.5194/acp-2016-438, in review, 2016.

Bryant, R. G., Bigg, G. R., Mahowald, N. M., Eckardt, F. D., and Ross S. G.: Dust emission response to climate in southern Africa, J. Geophys, Res, 112, D09207, doi:10.1029/2005JD007025, 2007.

Cakmur, R. V., Miller, R. L., Perlwitz, J., Geogdzhayev, I. V., Ginoux, P., Koch, D., Kohfeld, K. E., Tegen, I., and Zender, C. S. Constraining the magnitude of the global dust cycle by minimizing the difference between a model and observations, J. Geophys. Res., 111, D06207, doi:10.1029/2005jd005791, 2006.

Chernoff, D. I. and Bertram, A. K.: Effects of sulfate coatings on the ice nucleation properties of a biological ice nucleus and several types of minerals, J. Geophys. Res., 115, D20205, doi:10.1029/2010JD014254, 2010.

Choi, Y.-S., Lindzen, R. S., Ho, C.-H., and Kim, J.: Space observations of cold-cloud phase change, P. Natl. Acad. Sci. USA, 107, 11211-11216, doi:10.1073/pnas.1006241107, 2010.

Conen, F., Morris, C. E., Leifeld, J., Yakutin, M. V., and Alewell, C.: Biological residues define the ice nucleation properties of soil dust, Atmos. Chem. Phys., 11, 9643-9648, doi:10.5194/acp-119643-2011, 2011.

Creamean, J. M., Suski, K. J., Rosenfeld, D., Cazorla, A., DeMott, P. J., Sullivan, R. C., White, A. B., Ralph, F. M., Minnis, P., Comstock, J. M., Tomlinson, J. M., and Prather, K. A.: Dust and biological aerosols from the Sahara and Asia influence precipitation in the Western U.S, Science, 339, 1572-1578, doi:10.1126/science.1227279, 2013.

Cziczo, D. J., Froyd, K. D., Gallavardin, S. J., Moehler, O., Benz, S., Saathoff, H., and Murphy, D. M.: Deactivation of ice nuclei due to atmospherically relevant surface coatings, Environ. Res. Lett., 4, 044013, doi:10.1088/1748-9326/4/4/044013, 2009.

Cziczo, D. J., Froyd, K. D., Hoose, C., Jensen, E. J., Diao, M., Zondlo, M. A., Smith, J. B., Twohy, C. H., and Murphy, D. M.: Clarifying the dominant sources and mechanisms of cirrus cloud formation, Science, 340, 1320-1324, doi:10.1126/science.1234145, 2013.

DeMott, P. J., Cziczo, D. J., Prenni, A. J., Murphy, D. M., Kreidenweis, S. M., Thomson, D. S., Borys, R., and Rogers, D. C.: Measurements of the concentration and composition of nuclei for cirrus formation, P. Natl. Acad. Sci. USA, 100, 14655-14660, doi:10.1073/pnas.2532677100, 2003.

DeMott, P.J., Prenni, A. J., Liu, X., Kreidenweis, S. M., Petters, M. D., Twohy, C. H., Richardson, M. S., Eidhammer, T., and Rogers, D. C.: Predicting global atmospheric ice nuclei distributions and their impacts on climate, P. Natl. Acad. Sci. USA, 107, 1121711222, doi:10.1073/pnas.0910818107, 2010.

DeMott, P. J., Möhler, O., Stetzer, O., Vali, G., Levin, Z., Petters, M. D., Murakami, M., Leisner, T., Bundke, U., Klein, H., Kanji, Z. A., Cotton, R., Jones, H., Benz, S., Brinkmann, M., Rzesanke, D., Saathoff, H., Nicolet, M., Saito, A., Nillius, B., Bingemer, H., Abbatt, J., Ardon, K., Ganor, E., Georgakopoulos, D. G., and Saunders, C.: Resurgence in ice nuclei measurement research, B. Am. Meteorol. Soc., 92, 1623-1635, doi:10.1175/2011BAMS3119.1, 2011.

DeMott, P. J., Prenni, A. J., McMeeking, G. R., Sullivan, R. C., Petters, M. D., Tobo, Y., Niemand, M., Möhler, O., Snider, J. 
R., Wang, Z., and Kreidenweis, S. M.: Integrating laboratory and field data to quantify the immersion freezing ice nucleation activity of mineral dust particles, Atmos. Chem. Phys., 15, 393-409, doi:10.5194/acp-15-393-2015, 2015.

Emersic, C., Connolly, P. J., Boult, S., Campana, M., and Li, Z.: Investigating the discrepancy between wet-suspension- and drydispersion-derived ice nucleation efficiency of mineral particles, Atmos. Chem. Phys., 15, 11311-11326, doi:10.5194/acp15-11311-2015, 2015.

Engelstaedter, S., Tegen, I., and Washington, R.: North African dust emissions and transport, Earth-Sci. Rev., 79, 73-100, doi:10.1016/j.earscirev.2006.06.004, 2006.

Formenti, P., Schütz, L., Balkanski, Y., Desboeufs, K., Ebert, M., Kandler, K., Petzold, A., Scheuvens, D., Weinbruch, S., and Zhang, D.: Recent progress in understanding physical and chemical properties of African and Asian mineral dust, Atmos. Chem. Phys., 11, 8231-8256, doi:10.5194/acp-11-8231-2011, 2011.

Genthon, C.: Simulations of desert dust and sea-salt aerosols in Antarctica with a general circulation model of the atmosphere, Tellus B, 44, 371-389, doi:10.1034/j.1600-0889.1992.00014.x, 1992.

Ginoux, P., Prospero, J. M., Gill, T. E., Hsu, N. C., and Zhao, M.: Global-scale attribution of anthropogenic and natural dust sources and their emission rates based on MODIS Deep Blue aerosol products, Rev. Geophys., 50, RG3005, doi:10.1029/2012rg000388, 2012

Goudie, A. S. and Wells, G. L.: The nature, distribution and formation of pans in arid zones, Earth-Sci. Rev., 38, 1-69, doi:10.1016/0012-8252(94)00066-6, 1995.

Hallar, A. G., Chirokova, G., McCubbin, I., Painter, T. H., Wiedinmyer, C., and Dodson, C.: Atmospheric bioaerosols transported via dust storms in the western United States, Geophys. Res. Lett., 38, L17801, doi:10.1029/2011GL048166, 2011.

Harrison, A. D., Whale, T. F., Carpenter, M. A., Holden, M. A., Neve, L., O’Sullivan, D., Vergara Temprado, J., and Murray, B. J.: Not all feldspar is equal: a survey of ice nucleating properties across the feldspar group of minerals, Atmos. Chem. Phys. Discuss., doi:10.5194/acp-2016-136, in review, 2016.

Hartmann, S., Wex, H., Clauss, T., Augustin-Bauditz, S., Niedermeier, D., Rösch, M., and Stratmann, F.: Immersion freezing of kaolinite: scaling with particle surface area, J. Atmos. Sci., 73, 263-278, doi:10.1175/JAS-D-15-0057.1, 2016.

Hiranuma, N., Hoffmann, N., Kiselev, A., Dreyer, A., Zhang, K., Kulkarni, G., Koop, T., and Möhler, O.: Influence of surface morphology on the immersion mode ice nucleation efficiency of hematite particles, Atmos. Chem. Phys., 14, 2315-2324, doi:10.5194/acp-14-2315-2014, 2014.

Hiranuma, N., Augustin-Bauditz, S., Bingemer, H., Budke, C., Curtius, J., Danielczok, A., Diehl, K., Dreischmeier, K., Ebert, M., Frank, F., Hoffmann, N., Kandler, K., Kiselev, A., Koop, T., Leisner, T., Möhler, O., Nillius, B., Peckhaus, A., Rose, D., Weinbruch, S., Wex, H., Boose, Y., DeMott, P. J., Hader, J. D., Hill, T. C. J., Kanji, Z. A., Kulkarni, G., Levin, E. J. T., McCluskey, C. S., Murakami, M., Murray, B. J., Niedermeier, D., Petters, M. D., O'Sullivan, D., Saito, A., Schill, G. P., Tajiri, T., Tolbert, M. A., Welti, A., Whale, T. F., Wright, T. P., and Yamashita, K.: A comprehensive laboratory study on the immersion freezing behavior of illite NX particles: a comparison of 17 ice nucleation measurement techniques, Atmos. Chem. Phys., 15, 2489-2518, doi:10.5194/acp-15-2489-2015, 2015.

Hoose, C. and Möhler, O.: Heterogeneous ice nucleation on atmospheric aerosols: a review of results from laboratory experiments, Atmos. Chem. Phys., 12, 9817-9854, doi:10.5194/acp-12-98172012, 2012.

Hoose, C., Lohmann, U., Erdin, R., and Tegen, I.: The global influence of dust mineralogical composition on heterogeneous ice nucleation in mixed-phase clouds, Environ. Res. Lett., 3, 025003, doi:10.1088/1748-9326/3/2/025003, 2008.

Hoose, C., Kristjánsson, J. E., Chen, J.-P., and Hazra, A.: A classical-theory-based parameterization of heterogeneous ice nucleation by mineral dust, soot, and biological particles in a global climate model, J. Atmos. Sci., 67, 2483-2503, doi:10.1175/2010JAS3425.1, 2010.

Hoyle, C. R., Pinti, V., Welti, A., Zobrist, B., Marcolli, C., Luo, B., Höskuldsson, Á., Mattsson, H. B., Stetzer, O., Thorsteinsson, T., Larsen, G., and Peter, T.: Ice nucleation properties of volcanic ash from Eyjafjallajökull, Atmos. Chem. Phys., 11, 9911-9926, doi:10.5194/acp-11-9911-2011, 2011.

Kamphus, M., Ettner-Mahl, M., Klimach, T., Drewnick, F., Keller, L., Cziczo, D. J., Mertes, S., Borrmann, S., and Curtius, J.: Chemical composition of ambient aerosol, ice residues and cloud droplet residues in mixed-phase clouds: single particle analysis during the Cloud and Aerosol Characterization Experiment (CLACE 6), Atmos. Chem. Phys., 10, 8077-8095, doi:10.5194/acp-10-8077-2010, 2010

Kandler, K., Schütz, L., Deutscher, C., Ebert, M., Hofmann, H., Jäckel, S., Jaenicke, R., Knippertz, P., Lieke, K., Massling, A., Petzold, A., Schladitz, A., Weinzierl, B., Wiedensohler, A., Zorn, S., and Weinbruch, S.: Size distribution, mass concentration, chemical and mineralogical composition and derived optical parameters of the boundary layer aerosol at Tinfou, Morocco, during SAMUM, Tellus B, 61, 32-50, doi:10.1111/j.16000889.2008.00385.x, 2009.

Kandler, K., Lieke, K., Benker, N., Emmel, C., Küpper, M., MüllerEbert, D., Ebert, M., Scheuvens, D., Schladitz, A., Schütz, L., and Weinbruch, S.: Electron microscopy of particles collected at Praia, Cape Verde, during the Saharan Mineral Dust Experiment: particle chemistry, shape, mixing state and complex refractive index, Tellus B, 63, 475-496, doi:10.1111/j.16000889.2011.00550.x, 2011a.

Kandler, K., Schütz, L., Jäckel, S., Lieke, K., Emmel, C., MüllerEbert, D., Ebert, M., Scheuvens, D., Schladitz, A., Šegvic, B., Wiedensohler, A., and Weinbruch, S.: Ground-based offline aerosol measurements at Praia, Cape Verde, during the Saharan Mineral Dust Experiment: microphysical properties and mineralogy, Tellus B, 63, 459-474, doi:10.1111/j.16000889.2011.00546.x, 2011b.

Kanitz, T., Seifert, P., Ansmann, A., Engelmann, R., Althausen, D., Casiccia, C., and Rohwer, E. G.: Contrasting the impact of aerosols at northern and southern midlatitudes on heterogeneous ice formation, Geophys. Res. Lett., 38, L17802, doi:10.1029/2011GL048532, 2011.

Knopf, D. A. and Koop, T.: Heterogeneous nucleation of ice on surrogates of mineral dust, J. Geophys. Res., 111, D12201, doi:10.1029/2005JD006894, 2006. 
Korolev, A. V., Isaac G. A., Cober, S. G., Strapp, J. W., and Hallett, J.: Microphysical characterization of mixed-phase clouds, Q. J. Roy. Meteor. Soc., 129, 39-65, doi:10.1256/qj.01.204, 2003.

Kulkarni, G. and Dobbie, S.: Ice nucleation properties of mineral dust particles: determination of onset $\mathrm{RH}_{i}$, IN active fraction, nucleation time-lag, and the effect of active sites on contact angles, Atmos. Chem. Phys., 10, 95-105, doi:10.5194/acp-10-95-2010, 2010.

Kulkarni, G., Sanders, C., Zhang, K., Liu, X., and Zhao, C.: Ice nucleation of bare and sulfuric acid-coated mineral dust particles and implication for cloud properties, J. Geophys. Res.-Atmos., 119, 9993-10011, doi:10.1002/2014JD021567, 2014.

Kumai, M.: Snow crystals and the identification of the nuclei in the Northern United States of America, J. Meteorol., 18, 139-150, doi:10.1175/1520-0469(1961)018<0139:SCATIO>2.0.CO;2, 1961.

Kumai, M. and Francis, K. E.: Nuclei in snow and ice crystals on the Greenland Ice Cap under natural and artificially stimulated conditions, J. Atmos. Sci., 19, 474-481, doi:10.1175/15200469(1962)019<0474:NISAIC>2.0.CO;2, 1962.

Laurent, B., Tegen, I., Heinold, B., Schepanski, K., Weinzierl, B., and Esselborn, M.: A model study of Saharan dust emissions and distributions during the SAMUM-1 campaign, J. Geophys. Res., 115, D21210, doi:10.1029/2009JD012995, 2010.

Li, F., Ginoux, P., and Ramaswamy, V.: Distribution, transport, and deposition of mineral dust in the Southern Ocean and Antarctica: Contribution of major sources, J. Geophys. Res., 113, D10207, doi:10.1029/2007JD009190, 2008.

Lohmann, U. and Diehl, K.: Sensitivity studies of the importance of dust ice nuclei for the indirect aerosol effect on stratiform mixed-phase clouds, J. Atmos. Sci., 63, 968-982, doi:10.1175/JAS3662.1, 2006.

Lüönd, F., Stetzer, O., Welti, A., and Lohmann, U.: Experimental study on the ice nucleation ability of size-selected kaolinite particles in the immersion mode, J. Geophys. Res., 115, D14201, doi:10.1029/2009JD012959, 2010.

Marcolli, C.: Deposition nucleation viewed as homogeneous or immersion freezing in pores and cavities, Atmos. Chem. Phys., 14, 2071-2104, doi:10.5194/acp-14-2071-2014, 2014.

Marcolli, C., Gedamke, S., Peter, T., and Zobrist, B.: Efficiency of immersion mode ice nucleation on surrogates of mineral dust, Atmos. Chem. Phys., 7, 5081-5091, doi:10.5194/acp-7-50812007, 2007.

Maring, H., Savoie, D. L., Izaguirre, M. A., Custals, L., and Reid, J. S.: Mineral dust aerosol size distribution change during atmospheric transport, J. Geophys. Res., 108, 8592, doi:10.1029/2002JD002536, 2003.

Möhler, O., Field, P. R., Connolly, P., Benz, S., Saathoff, H., Schnaiter, M., Wagner, R., Cotton, R., Krämer, M., Mangold, A., and Heymsfield, A. J.: Efficiency of the deposition mode ice nucleation on mineral dust particles, Atmos. Chem. Phys., 6, 30073021, doi:10.5194/acp-6-3007-2006, 2006.

Möhler, O., Benz, S., Saathoff, H., Schnaiter, M., Wagner, R., Schneider, J., Walter, S., Ebert, V., and Wagner, S.: The effect of organic coating on the heterogeneous ice nucleation efficiency of mineral dust aerosols, Environ. Res. Lett., 3, 025007 , doi:10.1088/1748-9326/3/2/025007, 2008.

Murray, B. J., O'Sullivan, D., Atkinson, J. D., and Webb, M. E.: Ice nucleation by particles immersed in supercooled cloud droplets,
Chem. Soc. Rev., 41, 6519-6554, doi:10.1039/c2cs35200a, 2012.

Nagare, B., Marcolli, C., Welti, A., Stetzer, O., and Lohmann, U.: Comparing contact and immersion freezing from continuous flow diffusion chambers, Atmos. Chem. Phys., 16, 8899-8914, doi:10.5194/acp-16-8899-2016, 2016.

Niedermeier, D., Hartmann, S., Shaw, R. A., Covert, D., Mentel, T. F., Schneider, J., Poulain, L., Reitz, P., Spindler, C., Clauss, T., Kiselev, A., Hallbauer, E., Wex, H., Mildenberger, K., and Stratmann, F.: Heterogeneous freezing of droplets with immersed mineral dust particles - measurements and parameterization, Atmos. Chem. Phys., 10, 3601-3614, doi:10.5194/acp-10-36012010, 2010.

Niedermeier, D., Hartmann, S., Clauss, T., Wex, H., Kiselev, A., Sullivan, R. C., DeMott, P. J., Petters, M. D., Reitz, P., Schneider, J., Mikhailov, E., Sierau, B., Stetzer, O., Reimann, B., Bundke, U., Shaw, R. A., Buchholz, A., Mentel, T. F., and Stratmann, F.: Experimental study of the role of physicochemical surface processing on the IN ability of mineral dust particles, Atmos. Chem. Phys., 11, 11131-11144, doi:10.5194/acp-11-11131-2011, 2011.

Niedermeier, N., Held, A., Müller, T., Heinold, B., Schepanski, K., Tegen, I., Kandler, K., Ebert, M., Weinbruch, S., Read, K., Lee, J., Fomba, K. W., Müller, K., Herrmann, H., and Wiedensohler, A.: Mass deposition fluxes of Saharan mineral dust to the tropical northeast Atlantic Ocean: an intercomparison of methods, Atmos. Chem. Phys., 14, 2245-2266, doi:10.5194/acp-14-22452014, 2014.

Niemand, M., Möhler, O., Vogel, B., Vogel, H., Hoose, C., Connolly, P., Klein, H., Bingemer, H., DeMott, P., Skrotzki, J., and Leisner T.: A particle-surface-area-based parameterization of immersion freezing on desert dust particles, J. Atmos. Sci., 69, 3077-3092, doi:10.1175/JAS-D-11-0249.1, 2012.

O’Sullivan, D., Murray, B. J., Malkin, T. L., Whale, T. F., Umo, N. S., Atkinson, J. D., Price, H. C., Baustian, K. J., Browse, J., and Webb, M. E.: Ice nucleation by fertile soil dusts: relative importance of mineral and biogenic components, Atmos. Chem. Phys., 14, 1853-1867, doi:10.5194/acp-14-1853-2014, 2014.

Peckhaus, A., Kiselev, A., Hiron, T., Ebert, M., and Leisner, T.: A comparative study of $\mathrm{K}$-rich and $\mathrm{Na} / \mathrm{Ca}$-rich feldspar ice nucleating particles in a nanoliter droplet freezing assay, Atmos. Chem. Phys. Discuss., doi:10.5194/acp-2016-72, in review, 2016.

Pinti, V., Marcolli, C., Zobrist, B., Hoyle, C. R., and Peter, T.: Ice nucleation efficiency of clay minerals in the immersion mode, Atmos. Chem. Phys., 12, 5859-5878, doi:10.5194/acp-12-58592012, 2012.

Pratt, K. A., DeMott, P. J., French, J. R., Wang, Z., Westphal, D. L., Heymsfield, A. J., Twohy, C. H., Prenni, A. J., and Prather, K. A.: In situ detection of biological particles in cloud ice-crystals, Nat. Geosci., 2, 398-401, doi:10.1038/NGEO521, 2009.

Prospero, J. M., Ginoux, P., Torres, O., Nicholson, S. E., and Gill, T. E.: Environmental characterization of global sources of atmospheric soil dust identified with the nimbus 7 total ozone mapping spectrometer (TOMS) absorbing aerosol product, Rev. Geophys., 40, 1002, doi:10.1029/2000RG000095, 2002.

Pruppacher, H. R. and Klett, J. D.: Microphysics of clouds and precipitation, Kluwer Academic Publishers, Dordrecht, the Netherlands, 1997.

Reid, E. A., Reid, J. S., Meier, M. M., Dunlap, M. R., Cliff, S. S., Broumas, A., Perry K., and Maring H.: Characterization of 
African dust transported to Puerto Rico by individual particle and size segregated bulk analysis, J. Geophys. Res., 108, 8591, doi:10.1029/2002JD002935, 2003.

Reid, J. S., Hyer, E. J., Johnson, R. S., Holben, B. N., Yokelson, R. J., Zhang, J., Campbell, J. R., Christopher, S. A., Di Girolamo, L., Giglio, L., Holz, R. E., Kearney, C., Miettinen, J., Reid, E. A., Turk, F. J., Wang, J., Xian, P., Zhao, G., Balasubramanian, R., Chew, B. N., Janjai, S., Lagrosas, N., Lestari, P., Lin, N.H., Mahmud, M., Nguyen, A. X., Norris, B., Oanh, N. T. K., Oo, M., Salinas, S. V., Welton, E. J., and Liew, S. C.: Observing and understanding the Southeast Asian aerosol system by remote sensing: An initial review and analysis for the Seven Southeast Asian Studies (7SEAS) program, Atmos. Res., 122, 403-468, doi:10.1016/j.atmosres.2012.06.005, 2013.

Revel-Rolland, M., De Deckker, P., Delmonte, B., Hesse, P. P., Magee, J. W., Basile-Doelsch, I., Grousset, F., and Bosch, D.: Eastern Australia: A possible source of dust in East Antarctica interglacial ice, Earth Planetary Sci. Lett., 249, 1-13, doi:10.1016/j.eps1.2006.06.028, 2006.

Rietveld, H. M.: Line profiles of neutron powder-diffraction peaks for structure refinement, Acta Crystallogr., 22, 151-152, doi:10.1107/S0365110X67000234, 1967.

Rietveld, H. M.: A profile refinement method for nuclear and magnetic structures, J. Appl. Crystallogr., 2, 65-71, doi:10.1107/S0021889869006558, 1969.

Sassen, K., DeMott, P. J., Prospero, J. M., and Poellot, M. R.: Saharan dust storms and indirect aerosol effects on clouds: CRYSTAL-FACE results, Geophys. Res. Lett., 30, 1633, doi:10.1029/2003GL017371, 2003.

Seifert, P., Ansmann, A., Mattis, I., Wandinger, U., Tesche, M., Engelmann, R., Müller, D., Pérez, C., and Haustein, K.: Saharan dust and heterogeneous ice formation: Eleven years of cloud observations at a central European EARLINET site, J. Geophys. Res., 115, D20201, doi:10.1029/2009JD013222, 2010.

Sullivan, R. C., Petters, M. D., DeMott, P. J., Kreidenweis, S. M., Wex, H., Niedermeier, D., Hartmann, S., Clauss, T., Stratmann, F., Reitz, P., Schneider, J., and Sierau, B.: Irreversible loss of ice nucleation active sites in mineral dust particles caused by sulphuric acid condensation, Atmos. Chem. Phys., 10, 1147111487, doi:10.5194/acp-10-11471-2010, 2010a.

Sullivan, R. C., Miñambres, L., DeMott, P. J., Prenni, A. J., Carrico, C. M., Levin, E. J. T., and Kreidenweis, S. M.: Chemical processing does not always impair heterogeneous ice nucleation of mineral dust particles, Geophys. Res. Lett., 37, L24805, doi:10.1029/2010GL045540, 2010b.

Textor, C., Schulz, M., Guibert, S., Kinne, S., Balkanski, Y., Bauer, S., Berntsen, T., Berglen, T., Boucher, O., Chin, M., Dentener, F., Diehl, T., Feichter, J., Fillmore, D., Ginoux, P., Gong, S., Grini, A., Hendricks, J., Horowitz, L., Huang, P., Isaksen, I. S. A., Iversen, T., Kloster, S., Koch, D., Kirkevåg, A., Kristjansson, J. E., Krol, M., Lauer, A., Lamarque, J. F., Liu, X., Montanaro, V., Myhre, G., Penner, J. E., Pitari, G., Reddy, M. S., Seland, Ø., Stier, P., Takemura, T., and Tie, X.: The effect of harmonized emissions on aerosol properties in global models an AeroCom experiment, Atmos. Chem. Phys., 7, 4489-4501, doi:10.5194/acp-7-4489-2007, 2007.

Tobo, Y., DeMott, P. J., Raddatz, M., Niedermeier, D., Hartmann, S., Kreidenweis, S. M., Stratmann, F., and Wex, H.: Impacts of chemical reactivity on ice nucleation of kaolinite particles: A case study of levoglucosan and sulfuric acid, Geophys. Res. Lett., 39, L19803, doi:10.1029/2012GL053007, 2012.

Tobo, Y., DeMott, P. J., Hill, T. C. J., Prenni, A. J., SwobodaColberg, N. G., Franc, G. D., and Kreidenweis, S. M.: Organic matter matters for ice nuclei of agricultural soil origin, Atmos. Chem. Phys., 14, 8521-8531, doi:10.5194/acp-14-8521-2014, 2014.

Twohy, C. H. and Poellot, M. R.: Chemical characteristics of ice residual nuclei in anvil cirrus clouds: evidence for homogeneous and heterogeneous ice formation, Atmos. Chem. Phys., 5, 2289 2297, doi:10.5194/acp-5-2289-2005, 2005

Wagner, F., Bortoli, D., Pereira, S., Costa, M. J., Silva, A. M., Weinzierl, B., Esselborn, M., Petzold, A., Rasp, K., Heinold, B., and Tegen, I.: Properties of dust aerosol particles transported to Portugal from the Sahara desert, Tellus B, 61, 297-306, doi:10.1111/j.1600-0889.2008.00393.x, 2009.

Wang, B., Harder, T. H., Kelly, S. T., Piens, D. S., China, S., Kovarik, L., Keiluweit, M., Arey, B. W., Gilles, M. K., and Laskin, A.: Airborne soil organic particles generated by precipitation, Nat. Geosci. Lett., 9, 433-438, doi:10.1038/NGEO2705, 2016.

Washington, R., Todd, M., Middleton, N. J., and Goudie, A. S.: Dust-storm source areas determined by the total ozone monitoring spectrometer and surface observations, Ann. Assoc. Am. Geogr., 93, 297-313, doi:10.1111/1467-8306.9302003, 2003.

Welti, A., Lüönd, F., Kanji, Z. A., Stetzer, O., and Lohmann, U.: Time dependence of immersion freezing: an experimental study on size selected kaolinite particles, Atmos. Chem. Phys., 12, 9893-9907, doi:10.5194/acp-12-9893-2012, 2012.

Welti, A., Kanji, Z. A., Lüönd, F., Stetzer, O., and Lohmann, U: Exploring the mechanisms of ice nucleation on kaolinite: from deposition nucleation to condensation freezing, J. Atmos. Sci., 71, 16-36, doi:10.1175/JAS-D-12-0252.1, 2014.

Wex, H., DeMott, P. J., Tobo, Y., Hartmann, S., Rösch, M., Clauss, T., Tomsche, L., Niedermeier, D., and Stratmann, F.: Kaolinite particles as ice nuclei: learning from the use of different kaolinite samples and different coatings, Atmos. Chem. Phys., 14, 5529 5546, doi:10.5194/acp-14-5529-2014, 2014.

Wheeler, M. J., Mason, R. H., Steunenberg, K., Wagstaff, M., Chou, C., and Bertram, A. K.: Immersion freezing of supermicron mineral dust particles: freezing results, testing different schemes for describing ice nucleation, and ice nucleation active site densities, J. Phys. Chem. A, 119, 4358-4372, doi:10.1021/jp507875q, 2015.

Wiacek, A. and Peter, T.: On the availability of uncoated mineral dust ice nuclei in cold cloud regions, Geophys. Res. Lett., 36, L17801, doi:10.1029/2009GL039429, 2009.

Wiacek, A., Peter, T., and Lohmann, U.: The potential influence of Asian and African mineral dust on ice, mixed-phase and liquid water clouds, Atmos. Chem. Phys., 10, 8649-8667, doi:10.5194/acp-10-8649-2010, 2010.

Winckler, G., Anderson, R. F., Fleisher, M. Q., McGee, D., and Mahowald, N.: Covariant glacial-interglacial dust fluxes in the equatorial Pacific and Antarctica, Science, 320, 93-96, doi:10.1126/science.1150595, 2008.

Zender, C. S., Miller, R. L., and Tegen, I.: Quantifying mineral dust mass budgets: Terminology, constraints, and current estimates, Eos Trans. AGU, 85, 509-512, doi:10.1029/2004EO480002, 2004. 
Zobrist, B., Marcolli, C., Koop, T., Luo, B. P., Murphy, D. M., Lohmann, U., Zardini, A. A., Krieger, U. K., Corti, T., Cziczo, D. J., Fueglistaler, S., Hudson, P. K., Thomson, D. S., and Peter, T.: Oxalic acid as a heterogeneous ice nucleus in the upper troposphere and its indirect aerosol effect, Atmos. Chem. Phys., 6, 3115-3129, doi:10.5194/acp-6-3115-2006, 2006.
Zolles, T., Burkart, J., Häusler, T., Pummer, B., Hitzenberger, R., and Grothe, H.: Identification of ice nucleation active sites on feldspar dust particles, J. Phys. Chem. A, 119, 2692-2700, doi:10.1021/jp509839x, 2015. 